\title{
Heterologous Biosynthesis of Tetrahydroxanthone Dimers: Determination of Key Factors for Selective or Divergent Synthesis
}

Xingxing Wei, ${ }^{\dagger}$ Xiaoxuan Chen,${ }^{\dagger}$ Lin Chen,${ }^{\dagger}$ Dexiu Yan,${ }^{\dagger}$ Wei-Guang Wang,${ }^{\ddagger}$ and Yudai Matsuda $* \dagger$

'Department of Chemistry, City University of Hong Kong, Tat Chee Avenue, Kowloon, Hong Kong SAR, China *Key Laboratory of Chemistry in Ethnic Medicinal Resources, State Ethnic Affairs Commission and Ministry of Education, Yunnan Minzu University, Kunming 650031, China

*Correspondence should be addressed to Yudai Matsuda (ymatsuda@cityu.edu.hk).

\section{Table of Contents}

Supplementary Tables S1-S5 
Table S1. Primers used in this study.

\begin{tabular}{l|l}
\hline Primer & Sequence (5' to ${ }^{\prime}$ ) \\
\hline PenoA-F & TCAGTCTAGAGGATCGTGAAAGGCGCCAACGACGACTG \\
\hline PenoA-R & ACATTAATCCGGATCCTTTCCTATAATAGACTAGCG \\
\hline nsrQ-F & TCGAGCTCGGTACCCATGCCTGCACCAGCTGAAGT \\
\hline nsrQ-R & CTACTACAGATCCCCTAACTAAACTTCGCTCCCAG \\
\hline AacuC-F & TCGAGCTCGGTACCCATGGTGTCAAACGAGTATCTCAC \\
\hline AacuC-R & CTACTACAGATCCCCCTAATCCCAATCACCATCCAAAAGG \\
\hline AacuE-F & TCGAGCTCGGTACCCATGGATGCGACCTACACAGATC \\
\hline AacuE-R & CTACTACAGATCCCCGCACACTGCACATTCTCAC \\
\hline AacuF-F & TCGAGCTCGGTACCCATGCCGTCCTATCTCATCACCG \\
\hline AacuF-R & CTACTACAGATCCCCTCACAACCACTGTTTATTCCCCAAG \\
\hline AacuH-F & TCGAGCTCGGTACCCATGGGCTCCACCGCAACCGAAACC \\
\hline AacuH-R & CTACTACAGATCCCCTAAGCAAGATCTGGCCGGATCTTCC \\
\hline AacuP-F & TCGAGCTCGGTACCCATGCCCGCCCCCGCCGCAACCCAAA \\
\hline AacuP-R & CTACTACAGATCCCCTCAAGCCTCCTCCTGCCCCTTAATATAC \\
\hline AacuQ-F & AATTCGAGCTCGGTACCCATGGCAACAGCAACCGT \\
\hline AacuQ-R & GCTACTACAGATCCCCAACTATCGCCTCGTAGCTAAG \\
\hline InF-pUNA_Xbal-F & GAAAGGATCCTCTAGCCCATCATGGTGTTTTGATC \\
\hline InF-pUNA_Xbal-R & GCAGGTCGACTCTAGGTAAGATACATGAGCTTCGG \\
\hline InF-pPTRI_Smal-F & CTCTAGAGGATCCCCATCATGGTGTTTTGATC \\
\hline InF-pPTRI_Smal-R & TCGAGCTCGGTACCCGTAAGATACATGAGCTTCGG \\
\hline InF-pPTRI_HindIII-F & TGATTACGCCAAGCTCCCATCATGGTGTTTTGATC \\
\hline InF-linker-F1 & GCAGGCATGCAAGCTGTAAGATACATGAGCTTCGG \\
\hline InF-linker-R1 & GCTCGCGAGCGCGTTCCACTGCATCATCAGTCTAG \\
\hline InF-linker-R2 & AACGCGCTCGCGAGCAAGTACCATACAGTACCGCG \\
\hline TCGCGTGCGCGTTTACCCATCATGGTGTTTTGATC \\
\hline TAAACGCGCACGCGACATTAATCCGGATCCTTTCC \\
\hline
\end{tabular}


Table S2. Plasmids constructed in this study and PCR conditions for the amplification of the inserts for the plasmid constructions.

\begin{tabular}{|c|c|c|c|c|c|}
\hline Plasmid & Inserts & Primer 1 & Primer 2 & PCR Template & Vector \\
\hline pTAex3-AacuH & AacuH & AacuH-F & AacuH-R & gDNA & pTAex3 digested with Smal \\
\hline pTAex3-AacuF & AacuF & AacuF-F & AacuF-R & gDNA & pTAex3 digested with Smal \\
\hline pTAex3-AacuE & AacuE & AacuE-F & AacuE-R & gDNA & pTAex3 digested with Smal \\
\hline pTAex3-AacuQ & AacuQ & AacuQ-F & AacuQ-R & gDNA & pTAex3 digested with Smal \\
\hline pTAex3-AacuC & AacuC & AacuC-F & AacuC-R & gDNA & pTAex3 digested with Smal \\
\hline pTAex3-AacuP & AacuP & AacuP-F & AacuP-R & gDNA & pTAex3 digested with Smal \\
\hline pPTRI-AacuH & PamyB-AacuH-TamyB & In-pPTRI_Smal-F & In-pPTRI_Smal-R & pTAex3-AacuH & pPTRI digested with Smal \\
\hline pPTRI-nsrF & PamyB-nsrF-TamyB & In-pPTRI_Smal-F & In-pPTRI_Smal-R & pTAex3-nsrF ${ }^{1}$ & pPTRI digested with Smal \\
\hline pPTRI+AacuH+nsrG+nsrK & $\begin{array}{l}\text { PamyB-nsrG-TamyB } \\
\text { PamyB-nsrK-TamyB } \\
\text { PamyB-AacuH-TamyB }\end{array}$ & $\begin{array}{l}\text { In-pPTRI_Smal-F } \\
\text { InF-linker-F1 } \\
\text { InF-linker-F2 } \\
\end{array}$ & $\begin{array}{l}\text { InF-linker-R1 } \\
\text { InF-linker-R2 } \\
\text { In-pPTRI_Smal-R } \\
\end{array}$ & $\begin{array}{l}\text { pTAex3-nsrG }^{1} \\
\text { pTAex3-nsrK }{ }^{1} \\
\text { pTAex3-AacuH }\end{array}$ & pPTRI digested with Smal \\
\hline pUNA-nsrQ & PamyB-nsrQ-TamyB & nsrQ-F & $n s r Q-R$ & gDNA & pUNA digested with Smal \\
\hline pUNA-nsrQ+AacuF & PamyB-AacuF-TamyB & InF-pUNA_Xbal-F & InF-pUNA_Xbal-R & pTAex3-AacuF & pUNA-nsrQ digested with $X b a l$ \\
\hline pUNA-nsrQ+AacuF+AacuE & $\begin{array}{l}\text { PamyB-AacuF-TamyB } \\
\text { PamyB-AacuE-TamyB }\end{array}$ & $\begin{array}{l}\text { InF-pUNA_Xbal-F } \\
\text { InF-linker-F1 }\end{array}$ & $\begin{array}{l}\text { InF-linker-R1 } \\
\text { InF-pUNA_Xbal-R }\end{array}$ & $\begin{array}{l}\text { pTAex3-AacuF } \\
\text { pTAex3-AacuE }\end{array}$ & pUNA-nsrQ digested with $X b a l$ \\
\hline pTAex3A-AacuH & AacuH & AacuH-F & AacuH-R & gDNA & pTAex3 digested with Smal \\
\hline pBARI-AacuH & $\begin{array}{l}\text { P-enoA142/Hsp12 5' } \\
\text {-UTR-AacuH-TamyB }\end{array}$ & In-pPTRI_Smal-F & In-pPTRI_Smal-R & pTAex3A-AacuH & pBARI digested with Smal \\
\hline $\begin{array}{l}\text { pPTRI- } \\
\text { AacuH+AacuQ+AacuC }\end{array}$ & $\begin{array}{l}\text { PamyB-AacuQ-TamyB } \\
\text { PamyB-AacuC-TamyB }\end{array}$ & $\begin{array}{l}\text { InF-pPTRI_Hindll-F } \\
\text { InF-linker-F1 }\end{array}$ & $\begin{array}{l}\text { InF-linker-R1 } \\
\text { InF-pPTRI_HindIII-R }\end{array}$ & $\begin{array}{l}\text { pTAex3-AacuQ } \\
\text { pTAex3-AacuC }\end{array}$ & pPTRI-AacuH digested with HindIII \\
\hline pBARI-AacuP & PamyB-AacuP-TamyB & InF-pPTRI-Smal-F & InF-pPTRI-Smal-R & pTAex3-AacuP & pBARI digested with Smal \\
\hline $\begin{array}{l}\text { pBARI- } \\
\text { AacuP+AacuF+AacuE }\end{array}$ & $\begin{array}{l}\text { PamyB-AacuF-TamyB } \\
\text { PamyB-AacuE-TamyB }\end{array}$ & $\begin{array}{l}\text { InF-pPTRI_Hindll-F } \\
\text { InF-linker-F1 }\end{array}$ & $\begin{array}{l}\text { InF-linker-R1 } \\
\text { InF-pPTRI_HindII-F }\end{array}$ & $\begin{array}{l}\text { pTAex3-AacuF } \\
\text { pTAex3-AacuE }\end{array}$ & pBARI-AacuP digested with HindIII \\
\hline
\end{tabular}

Table S3. Aspergillus oryzae transformants constructed in this study.

\begin{tabular}{|l|l|l|}
\hline Strain & Host strain & Plasmids used for transformation \\
\hline A.oryzae /nsrBCDERJIF & A.oryzae /nsrBCDERJ/1 & pPTRI-nsrF \\
\hline A.oryzae /nsrBCDERJI+AacuH & A.oryzae /nsrBCDERJ/1 & pPTRI-AacuH \\
\hline A.oryzae /nsrBCDERJIGK+AacuH & A.oryzae /nsrBCDERJ/1 & pPTRI-AacuH+nsrG+nsrK \\
\hline A.oryzae /nsrBCDERJIGKQ+AacuHF & A.oryzae /nsrBCDERJIGK+AacuH & pUNA-nsrQ+AacuF \\
\hline A.oryzae /nsrBCDERJIGKQ+AacuHFE & A.oryzae /nsrBCDERJIGK+AacuH & pUNA-nsrQ+AacuF+AacuE \\
\hline A.oryzae /nsrBCDERJI+AacuHQC & A.oryzae /nsrBCDERJI & pPTRI-AacuH+AacuQ+AacuC \\
\hline A.oryzae /nsrBCDERJI+AacuHQCPFE & A.oryzae /nsrBCDERJI+AacuHQC & pBARI-AacuP+AacuF+AacuE \\
\hline A.oryzae /nsrBCDERJIGKQ+AacuHFE+AacuH (2nd copy) & A.oryzae /nsrBCDERJIGKQ+AacuHFE & pBARI-AacuH \\
\hline A.oryzae / AacuE & A. oryzae NSAR1 & pTAex3-AacuE \\
\hline
\end{tabular}


Table S4. NMR data for 10a'-epi-rugulotrosin A (10).

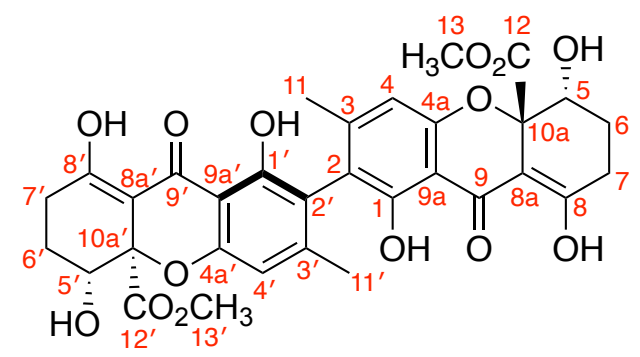

\begin{tabular}{|c|c|c|c|c|c|}
\hline position & $\delta_{c}$, type & $\delta_{\mathrm{H}}$, mult. $(\mathrm{J}$ in Hz) & HMBC correlation & COSY correlation & NOESY correlation \\
\hline 1 & $159.4, \mathrm{C}$ & & & & \\
\hline 2 & $117.4, \mathrm{C}$ & & & & \\
\hline 3 & 149.7, C & & & & \\
\hline 4 & $109.2, \mathrm{CH}$ & $6.52, \mathrm{~s}$ & $2,4 a, 9 a, 11$ & & $\mathrm{H}-11$ \\
\hline $4 a$ & $156.9, \mathrm{C}$ & & & & \\
\hline 5 & $67.2, \mathrm{CH}$ & $4.34, \mathrm{t}(1.8)$ & $8 a$ & $\mathrm{H}-6 \mathrm{a}, \mathrm{H}-6 \beta$ & $\mathrm{H}-6 \mathrm{a}, \mathrm{H}-6 \beta$ \\
\hline \multirow[t]{2}{*}{6} & $23.0, \mathrm{CH}_{2}$ & $2.15(a), m$ & & $\mathrm{H}-5, \mathrm{H}-6 \beta, \mathrm{H}-7 \mathrm{a}$ & $\mathrm{H}-5, \mathrm{H}-7 \mathrm{a}$ \\
\hline & & $1.95(\beta)$, dddd $(14.7,11.0,7.0,1.8)$ & & $\mathrm{H}-5, \mathrm{H}-6 \mathrm{a}, \mathrm{H}-7 \mathrm{a}, \mathrm{H}-7 \beta$ & $\mathrm{H}-5$ \\
\hline \multirow[t]{2}{*}{7} & $24.4, \mathrm{CH}_{2}$ & $2.83(a)$, ddd $(19.4,11.2,7.2)$ & 6,8 & 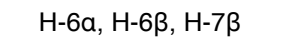 & $\mathrm{H}-6 \mathrm{a}$ \\
\hline & & $2.40(\beta), \mathrm{dd}(19.4,6.8)$ & 5,8 & $\mathrm{H}-6 \beta, \mathrm{H}-7 \mathrm{a}$ & \\
\hline 8 & $179.2, \mathrm{C}$ & & & & \\
\hline $8 a$ & $100.0, \mathrm{C}$ & & & & \\
\hline 9 & $186.9, \mathrm{C}$ & & & & \\
\hline $9 a$ & 105.0, C & & & & \\
\hline $10 a$ & $83.9, \mathrm{C}$ & & & & \\
\hline 11 & $20.8, \mathrm{CH}_{3}$ & $2.04, \mathrm{~s}$ & $2,3,4$ & & $\mathrm{H}-4$ \\
\hline 12 & $171.2, \mathrm{C}$ & & & & \\
\hline 13 & 53.6, $\mathrm{CH}_{3}$ & $3.75, \mathrm{~s}$ & 12 & & \\
\hline $1-\mathrm{OH}$ & & $11.62, \mathrm{~s}$ & $1,2,9 a$ & & \\
\hline $8-\mathrm{OH}$ & & $14.06, \mathrm{~s}$ & $7,8,8 a$ & & \\
\hline $1^{\prime}$ & $159.4, \mathrm{C}$ & & & & \\
\hline $2^{\prime}$ & 116.8, C & & & & \\
\hline $3^{\prime}$ & $150.2, \mathrm{C}$ & & & & \\
\hline $4^{\prime}$ & 109.3, CH & $6.56, \mathrm{~s}$ & $2^{\prime}, 4 a^{\prime}, 9 a^{\prime}, 11^{\prime}$ & & $\mathrm{H}-11^{\prime}$ \\
\hline $4 a^{\prime}$ & $157.9, \mathrm{C}$ & & & & \\
\hline $5^{\prime}$ & $72.0, \mathrm{CH}$ & $4.32, \mathrm{dd}(12.5,5.0)$ & & $H-6^{\prime} a, H-6^{\prime} \beta$ & $H-6^{\prime} \beta$ \\
\hline \multirow[t]{2}{*}{$6^{\prime}$} & 23.8, $\mathrm{CH}_{2}$ & $2.20(a), m$ & & $H-5^{\prime}, H-7^{\prime} a, H-7^{\prime} \beta$ & \\
\hline & & $2.10(\beta), \mathrm{m}$ & & $H-5^{\prime}, H-7^{\prime} a, H-7^{\prime} \beta$ & $H-5^{\prime}, H-7^{\prime} \beta$ \\
\hline \multirow[t]{2}{*}{$7^{\prime}$} & $27.5, \mathrm{CH}_{2}$ & $2.64(a)$, ddd $(19.4,7.4,1.8)$ & $5^{\prime}, 8^{\prime}$ & $H-6^{\prime} a, H-6^{\prime} \beta, H-7^{\prime} \beta$ & \\
\hline & & $2.68(\beta)$, ddd $(19.4,11.0,7.0)$ & $8^{\prime}$ & $H-6^{\prime} a, H-6^{\prime} \beta, H-7^{\prime} a$ & $H-6^{\prime} \beta$ \\
\hline $8^{\prime}$ & 177.7, C & & & & \\
\hline $8 a^{\prime}$ & 101.1, C & & & & \\
\hline $9^{\prime}$ & 186.7, C & & & & \\
\hline $9 a^{\prime}$ & $104.9, \mathrm{C}$ & & & & \\
\hline $10 a^{\prime}$ & $84.3, \mathrm{C}$ & & & & \\
\hline $11^{\prime}$ & $20.9, \mathrm{CH}_{3}$ & $2.02, \mathrm{~s}$ & $2^{\prime}, 3^{\prime}, 4^{\prime}$ & & $\mathrm{H}-4^{\prime}$ \\
\hline $12^{\prime}$ & $170.3, \mathrm{C}$ & & & & \\
\hline $13^{\prime}$ & $53.1, \mathrm{CH}_{3}$ & $3.75, \mathrm{~s}$ & $12^{\prime}$ & & \\
\hline $1^{\prime}-\mathrm{OH}$ & & $11.51, \mathrm{~s}$ & $1^{\prime}, 2^{\prime}, 9 a^{\prime}$ & & \\
\hline $8^{\prime}-\mathrm{OH}$ & & $13.89, \mathrm{~s}$ & $7^{\prime}, 8^{\prime}, 8 a^{\prime}$ & & \\
\hline
\end{tabular}

${ }^{1} \mathrm{H}$ NMR: $600 \mathrm{MHz},{ }^{13} \mathrm{C}$ NMR: $150 \mathrm{MHz}$ (in $\mathrm{CDCl}_{3}$ ) 
Table S5. NMR data for 10a'-epi-versixanthone H (12).

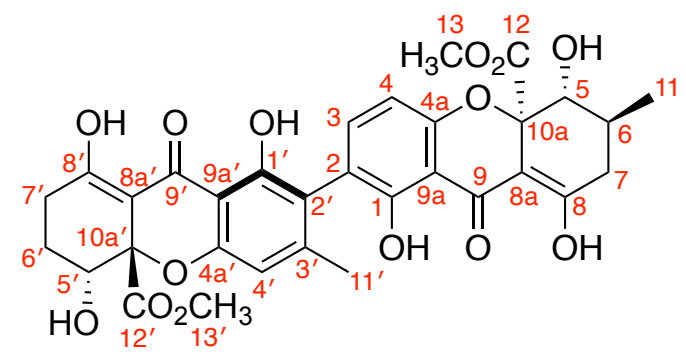

\begin{tabular}{|c|c|c|c|c|c|}
\hline position & $\delta_{c}$, type & $\delta_{\mathrm{H}}$, mult. $(\mathrm{J}$ in Hz$)$ & HMBC correlation & COSY correlation & NOESY correlation \\
\hline 1 & 159.7, C & & & & \\
\hline 2 & 116.9, C & & & & \\
\hline 3 & $140.9, \mathrm{CH}$ & $7.22, d(8.4)$ & $1,4 a, 2^{\prime}$ & $\mathrm{H}-4$ & $\mathrm{H}-4$ \\
\hline 4 & $107.8, \mathrm{CH}$ & $6.64, d(8.4)$ & $2,4 a, 9 a$ & $\mathrm{H}-3$ & $\mathrm{H}-3$ \\
\hline $4 a$ & $158.5, \mathrm{C}$ & & & & \\
\hline 5 & $77.0, \mathrm{CH}$ & $3.94, d(11.0)$ & $10 a, 12$ & $\mathrm{H}-6$ & $\mathrm{H}-6, \mathrm{H}-11$ \\
\hline 6 & $29.3, \mathrm{CH}$ & $2.42, \mathrm{~m}$ & & $\mathrm{H}-5, \mathrm{H}-7 \mathrm{a}, \mathrm{H}-7 \beta, \mathrm{H}-11$ & $\mathrm{H}-5, \mathrm{H}-7 \mathrm{a}, \mathrm{H}-11$ \\
\hline \multirow[t]{2}{*}{7} & $36.2, \mathrm{CH}_{2}$ & $2.74(a), d d(19.4,6.2)$ & 5,8 & $\mathrm{H}-6, \mathrm{H}-7 \beta$ & $\mathrm{H}-11$ \\
\hline & & $2.33(\beta), \mathrm{dd}(19.4,10.6)$ & $6,8,11$ & $\mathrm{H}-6, \mathrm{H}-7 \mathrm{a}$ & $\mathrm{H}-11$ \\
\hline 8 & 177.6, C & & & & \\
\hline $8 a$ & 101.5, C & & & & \\
\hline 9 & 187.1, C & & & & \\
\hline $9 a$ & 106.8, C & & & & \\
\hline $10 a$ & $84.8, \mathrm{C}$ & & & & \\
\hline 11 & $18.0, \mathrm{CH}_{3}$ & $1.18, d(6.2)$ & $5,6,7$ & $\mathrm{H}-6$ & \\
\hline 12 & $170.4, \mathrm{C}$ & & & & \\
\hline 13 & $53.2, \mathrm{CH}_{3}$ & $3.74, \mathrm{~s}$ & 12 & & \\
\hline $1-\mathrm{OH}$ & & $11.63, \mathrm{~s}$ & $1,2,9 a$ & & \\
\hline $8-\mathrm{OH}$ & & 13.77, brs & & & \\
\hline $1^{\prime}$ & 159.4, C & & & & \\
\hline $2^{\prime}$ & 118.6, C & & & & \\
\hline $3^{\prime}$ & 149.5, C & & & & \\
\hline $4^{\prime}$ & $109.1, \mathrm{CH}$ & $6.48, s$ & $2^{\prime}, 4 a^{\prime}, 9 a^{\prime}, 11^{\prime}$ & & $\mathrm{H}-11^{\prime}$ \\
\hline $4 a^{\prime}$ & 156.7, C & & & & \\
\hline $5^{\prime}$ & $67.2, \mathrm{CH}$ & $4.33, \mathrm{dd}(3.9,2.0)$ & & $H-6^{\prime} a, H-6^{\prime} \beta$ & $H-6^{\prime} a, H-6^{\prime} \beta$ \\
\hline \multirow[t]{2}{*}{$6^{\prime}$} & 23.0, $\mathrm{CH}_{2}$ & $2.17(\mathrm{a}), \mathrm{m}$ & & $H-5^{\prime}, H-6^{\prime} \beta, H-7^{\prime} a$ & $H-5^{\prime}, H-7^{\prime} a$ \\
\hline & & $1.94(\beta)$, dddd $(14.7,11.4,7.0,1.8)$ & & $H-5^{\prime}, H-6^{\prime} a, H-7^{\prime} a, H-7^{\prime} \beta$ & $\mathrm{H}-5^{\prime}, \mathrm{H}-7^{\prime} \beta$ \\
\hline \multirow[t]{2}{*}{$7^{\prime}$} & $24.4, \mathrm{CH}_{2}$ & $2.83(\mathrm{a}), \mathrm{ddd}(19.1,11.4,7.3)$ & $8^{\prime}$ & $H-6^{\prime} a, H-6^{\prime} \beta, H-7^{\prime} \beta$ & $H-6^{\prime} a$ \\
\hline & & $2.40(\beta)$, dd $(19.1,6.6)$ & $5^{\prime}, 8^{\prime}$ & $H-6^{\prime} \beta, H-7^{\prime} a$ & $H-6^{\prime} \beta$ \\
\hline $8^{\prime}$ & 179.2, C & & & & \\
\hline $8 a^{\prime}$ & 100.0, C & & & & \\
\hline $9^{\prime}$ & 186.9, C & & & & \\
\hline $9 a^{\prime}$ & $104.9, \mathrm{C}$ & & & & \\
\hline $10 a^{\prime}$ & 83.9, C & & & & \\
\hline $11^{\prime}$ & $21.2, \mathrm{CH}_{3}$ & $2.10, \mathrm{~s}$ & $2^{\prime}, 3^{\prime}, 4^{\prime}$ & & $\mathrm{H}-4^{\prime}$ \\
\hline $12^{\prime}$ & $171.2, \mathrm{C}$ & & & & \\
\hline $13^{\prime}$ & 53.6, $\mathrm{CH}_{3}$ & $3.74, \mathrm{~s}$ & $12^{\prime}$ & & \\
\hline $1^{\prime}-\mathrm{OH}$ & & $11.67, \mathrm{~s}$ & $1^{\prime}, 2^{\prime}, 9 a^{\prime}$ & & \\
\hline $8^{\prime}-\mathrm{OH}$ & & 14.05 , brs & & & \\
\hline
\end{tabular}

${ }^{1} \mathrm{H}$ NMR: $600 \mathrm{MHz},{ }^{13} \mathrm{C}$ NMR: $150 \mathrm{MHz}$ (in $\mathrm{CDCl}_{3}$ ) 

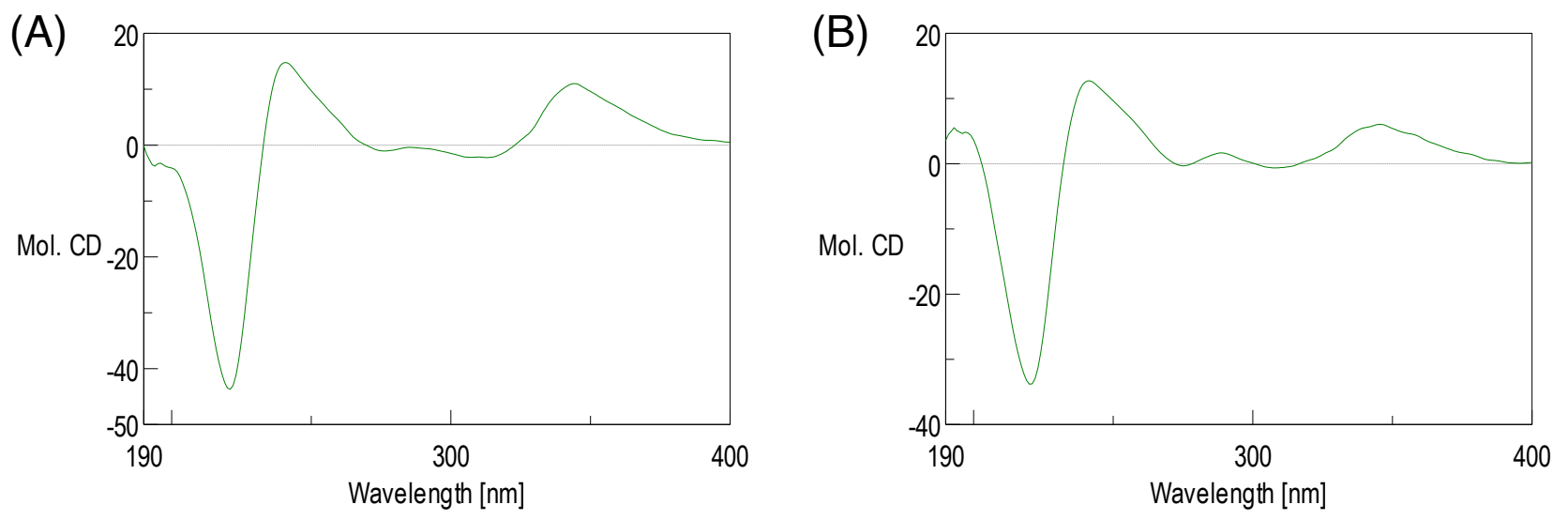

Figure S1. CD spectra of (A) 10a'-epi-rugulotrosin A (10) and (B) 10a'-epi-versixanthone H (12).

GTGAAAGGCGCCAACGACGACTGTCTCATTACTAGTCTACTAGTAACTCTGTCTTATCGTCATCTCCCATAGGTGAGTTTGGTTGTTTTG ITTCCACTGAGATCATGACCTCCTCCTACCCCACCATCCCACTATTTTTGTTACGGTAGCCATGACCCCTCCATGGAAATACTACCTTTT CAGGGCTCAAGCGTCGTGTCGGGCATTTATCGGGGGATGGACCAATCAGCGTAGGGATTCAAGCGTCGTGTCGGGCATTTATCGGGG GATGGACCAATCAGCGTAGGGATTCAAGCGTCGTGTCGGGCATTTATCGGGGGATGGACCAATCAGCGTAGGGATTCAAGCGTCGTG TCGGGCATTTATCGGGGGATGGACCAATCAGCGTAGGGATTCAAGCGTCGTGTCGGGCATTTATCGGGGGATGGACCAATCAGCGTA GGGATTCAAGCGTCGTGTCGGGCATTTATCGGGGGATGGACCAATCAGCGTAGGGATTCGAGAAATACTACCTTTTCAGGGCTCAAGC GTCGTGTCGGGCATTTATCGGGGGATGGACCAATCAGCGTAGGGATTCAAGCGTCGTGTCGGGCATTTATCGGGGGATGGACCAATC AGCGTAGGGATTCAAGCGTCGTGTCGGGCATTTATCGGGGGATGGACCAATCAGCGTAGGGATTCAAGCGTCGTGTCGGGCATTTAT CGGGGGATGGACCAATCAGCGTAGGGATTCAAGCGTCGTGTCGGGCATTTATCGGGGGATGGACCAATCAGCGTAGGGATTCAAGCG TCGTGTCGGGCATTTATCGGGGGATGGACCAATCAGCGTAGGGATATCGCAAAGAGAGAGGAGGACGAGGACGATCAGGAAACTGT GTCTCGCCGTCATACCACAATCGTGTTATCCTGATTGACATCTTCTTAAATATCGTTGTAACTGTTCCTGACTCTCGGTCAACTGAAATTG GATCTCCCCACCACTGCCTCTACCTTGTACTCCGTGACTGAACCATCCGATCATTCTTTTTGGGTCGTCGGTGAACACAACCCCCGCT GCTAGTCTCCTTCCAACACCGATCCAGAATTGTTTTGATTTTCCATTCCCTTCGTTTATATCTGTCGTCTCTCCTCCCTTTCCGTCTCTTT TATCAATTTCGACAAGACAAACAAACAAATCACAACTACTCTACCAATTACTACTCCTTTAACCACTTTCTACCTTTTACCAAACCACTCG CAAACGAATTCGAGCTCGGTACCCGGGGATCTGTAGTAGCTCGTGAAGGGTGGAGAGTATATGATGGTACTGCTATTCAATCTGGCATT GGACAGTGAGTTTGAGTTTGATGTACAGTTGGAGTCGTTACTGCTGTCATCCCCTTATACTCTTCGATTGTTTTTCGAACCCTAACGCC AAGCACGCTAGTCTATTATAGGAAAGGATCC

Figure S2. DNA fragment synthesized in this study. The DNA sequence contains P-enoA142 (cyan), 5' untranslated region of the Hsp12 gene (yellow), and TamyB (green). 


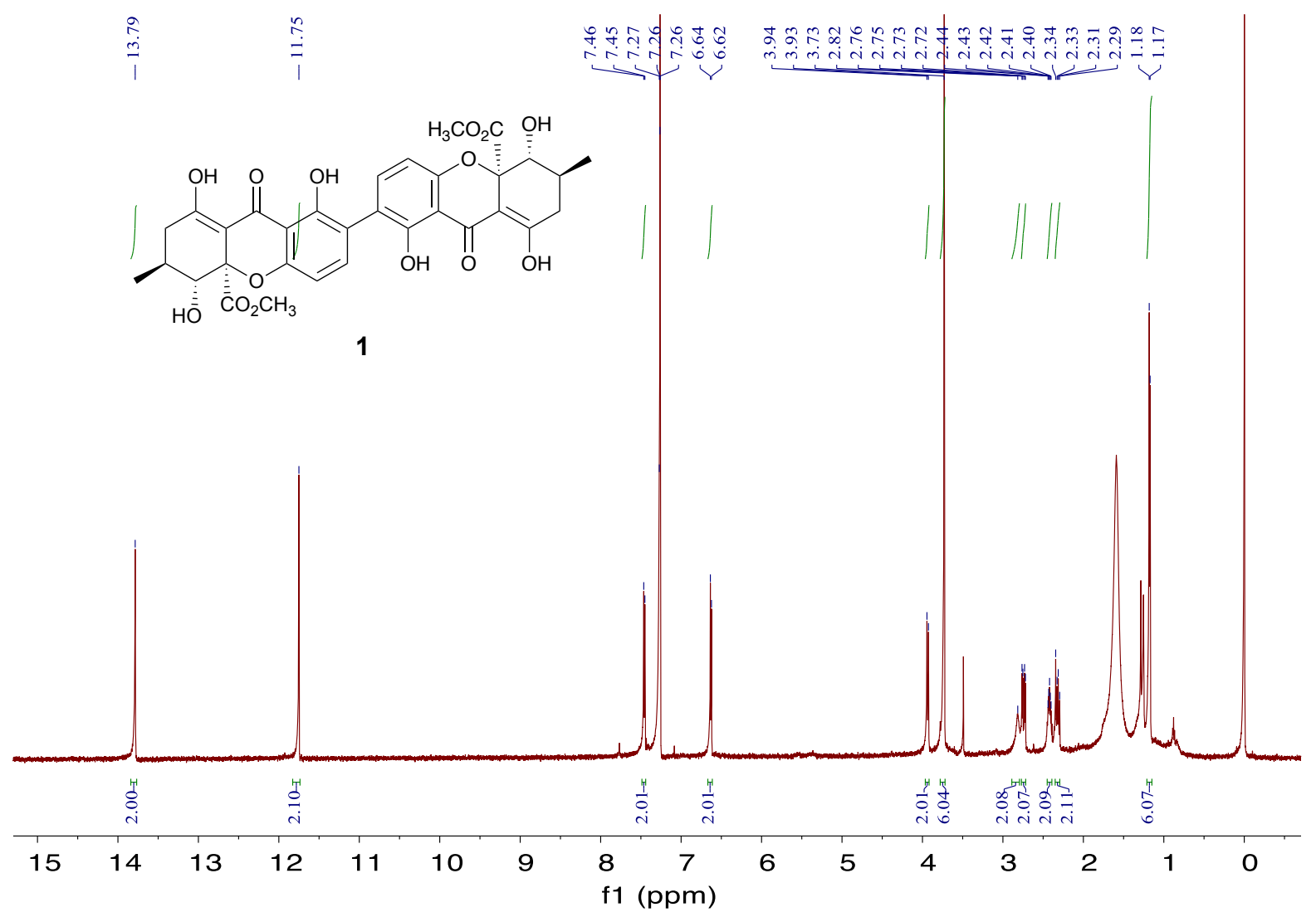

Figure S3. ${ }^{1} \mathrm{H}$ NMR spectrum of secalonic acid D (1) in $\mathrm{CDCl}_{3}$ at $600 \mathrm{MHz}$.
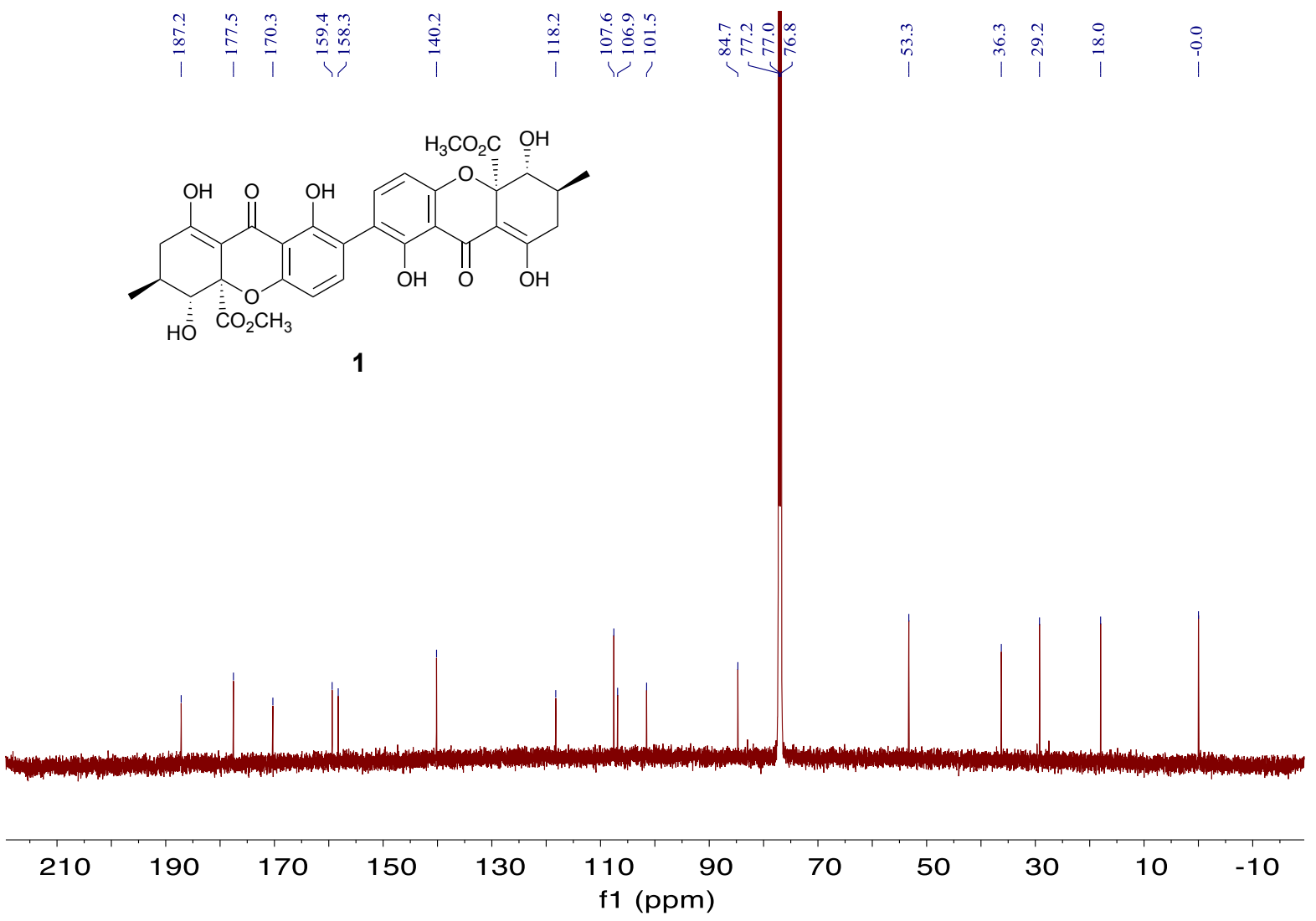

Figure S4. ${ }^{13} \mathrm{C}$ NMR spectrum of secalonic acid D (1) in $\mathrm{CDCl}_{3}$ at $150 \mathrm{MHz}$. 


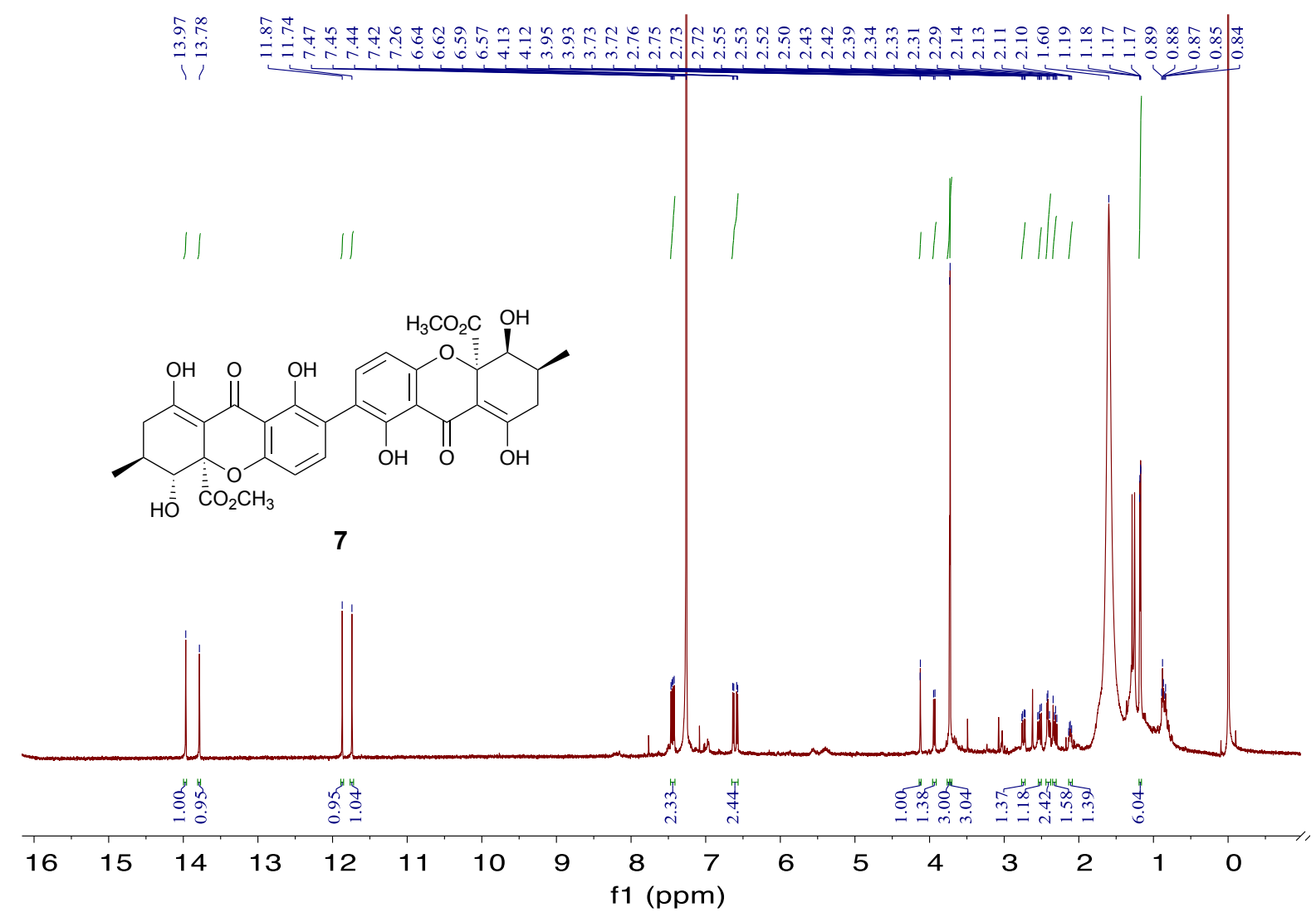

Figure S5. ${ }^{1} \mathrm{H}$ NMR spectrum of secalonic acid F (7) in $\mathrm{CDCl}_{3}$ at $600 \mathrm{MHz}$.

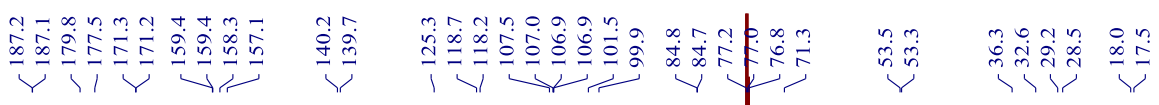

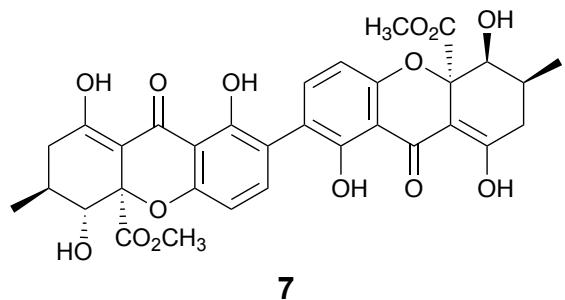

\begin{tabular}{|c|c|c|c|c|c|c|c|c|c|c|c|}
\hline 210 & 190 & 170 & 150 & 130 & $\begin{array}{c}110 \\
\mathrm{f} 1\end{array}$ & $\begin{array}{l}90 \\
\mathrm{~m})\end{array}$ & 70 & 50 & 30 & 10 & -10 \\
\hline
\end{tabular}

Figure S6. ${ }^{13} \mathrm{C}$ NMR spectrum of secalonic acid $\mathrm{F}(7)$ in $\mathrm{CDCl}_{3}$ at $150 \mathrm{MHz}$. 


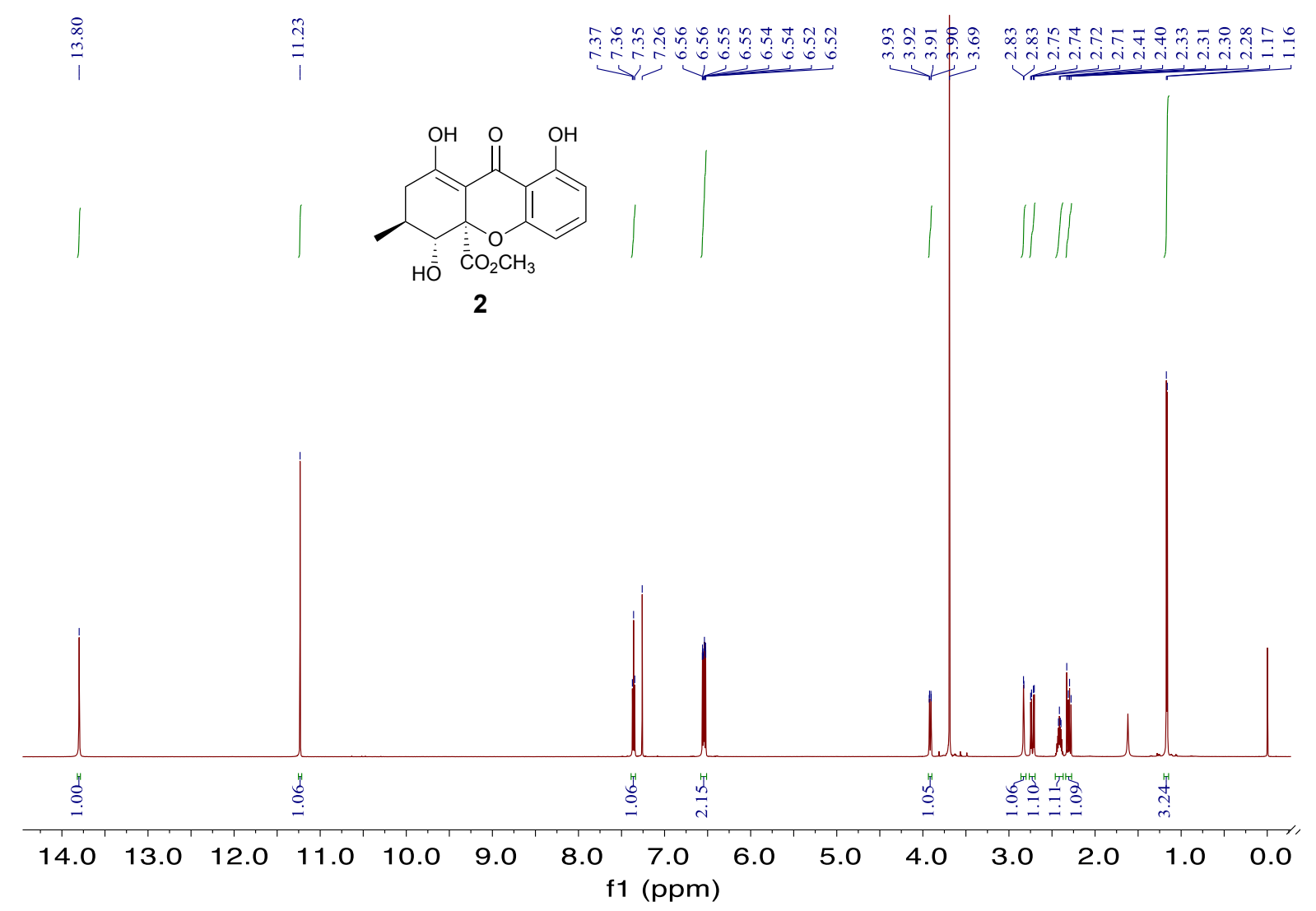

Figure S7. ${ }^{1} \mathrm{H}$ NMR spectrum of blennolide B (2) in $\mathrm{CDCl}_{3}$ at $600 \mathrm{MHz}$.
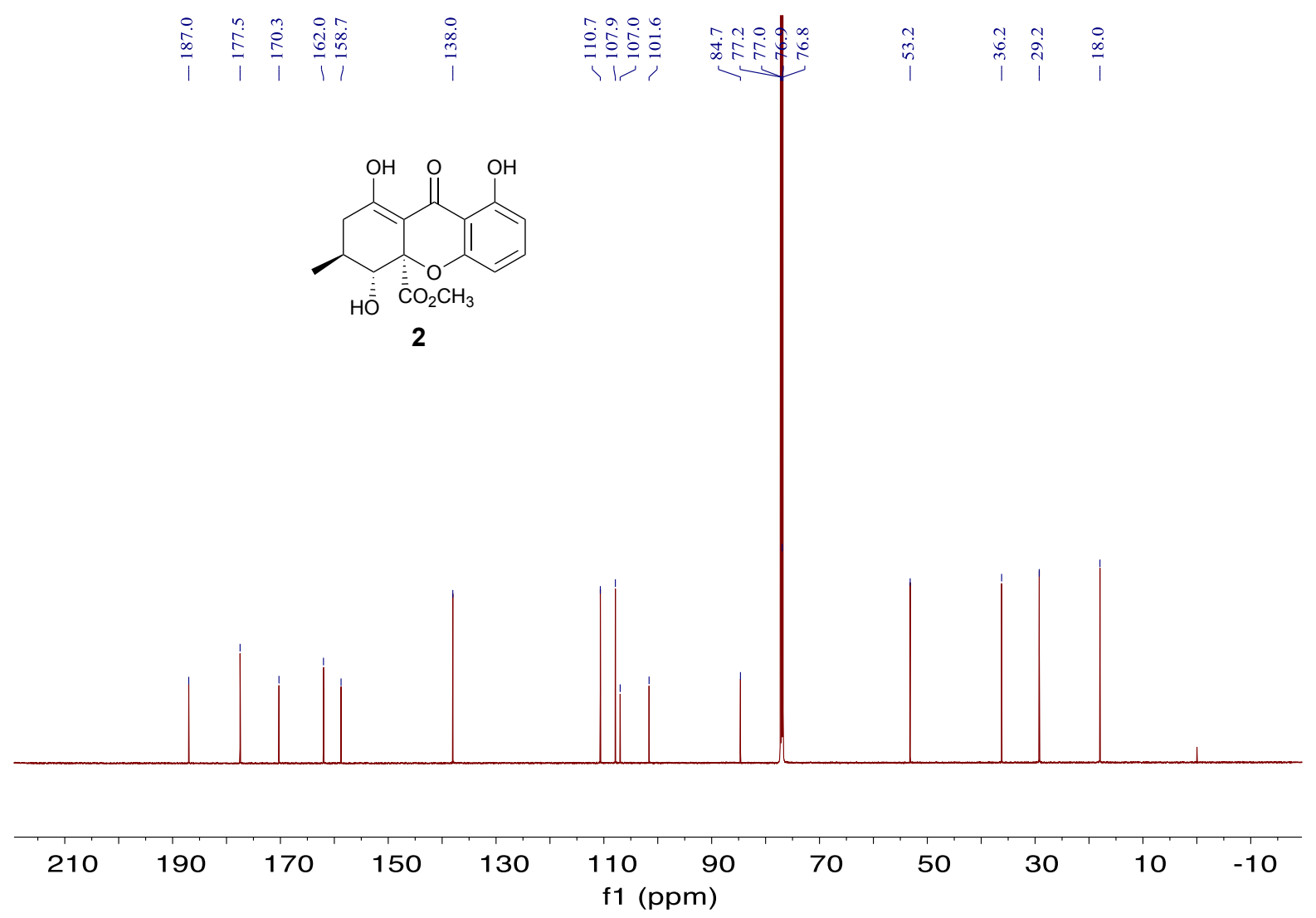

Figure S8. ${ }^{13} \mathrm{C}$ NMR spectrum of blennolide B (2) in $\mathrm{CDCl}_{3}$ at $150 \mathrm{MHz}$. 


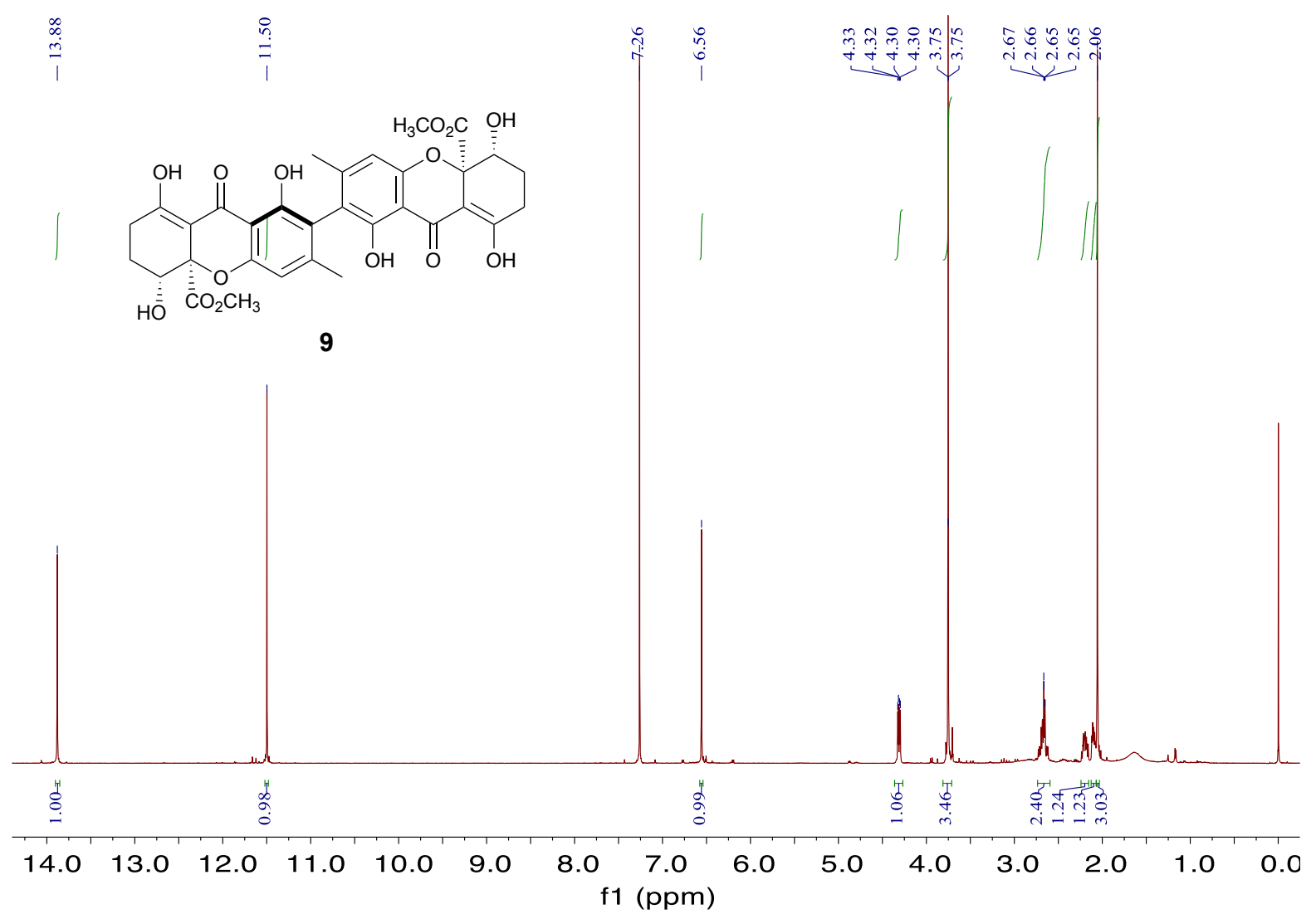

Figure S9. ${ }^{1} \mathrm{H}$ NMR spectrum of rugulotrosin $\mathrm{A}(9)$ in $\mathrm{CDCl}_{3}$ at $600 \mathrm{MHz}$.

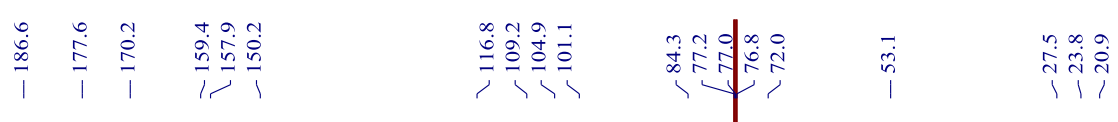
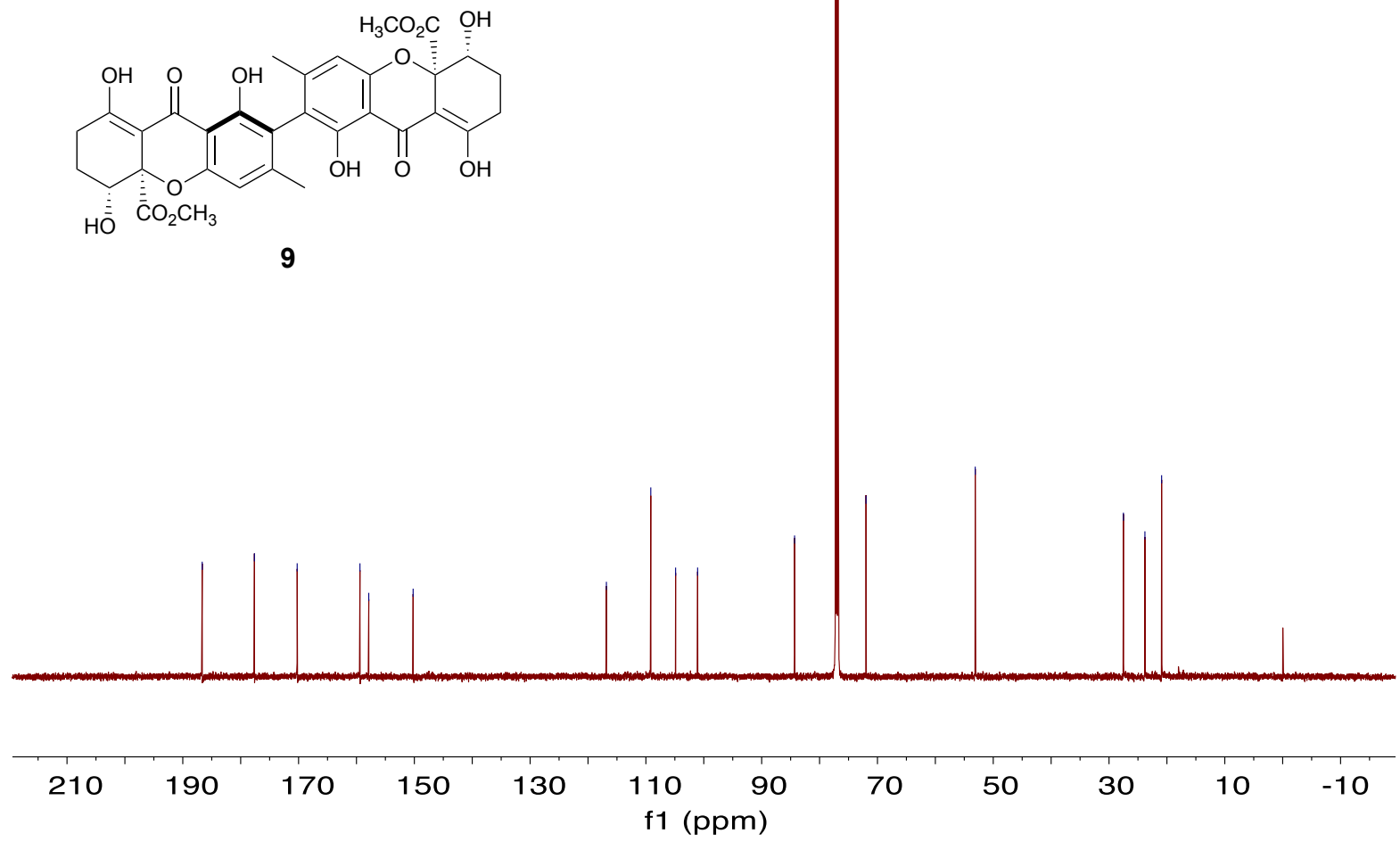

Figure S10. ${ }^{13} \mathrm{C}$ NMR spectrum of rugulotrosin $\mathrm{A}(9)$ in $\mathrm{CDCl}_{3}$ at $150 \mathrm{MHz}$. 


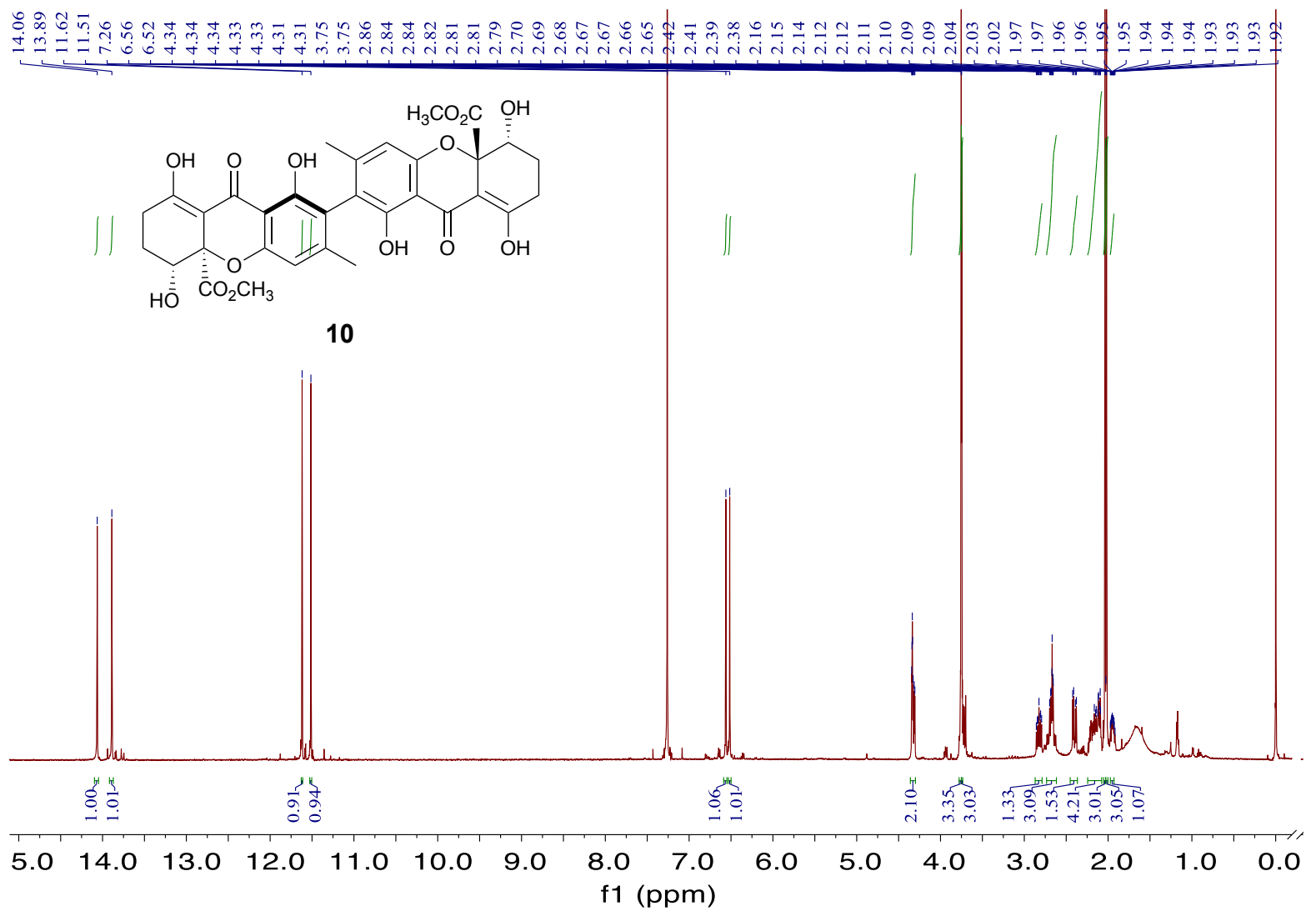

Figure S11. ${ }^{1} \mathrm{H}$ NMR spectrum of $10 \mathrm{a}^{\prime}$-epi-rugulotrosin $\mathrm{A}(\mathbf{1 0})$ in $\mathrm{CDCl}_{3}$ at $600 \mathrm{MHz}$.

لy

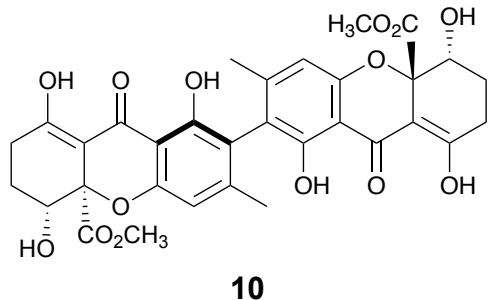

10

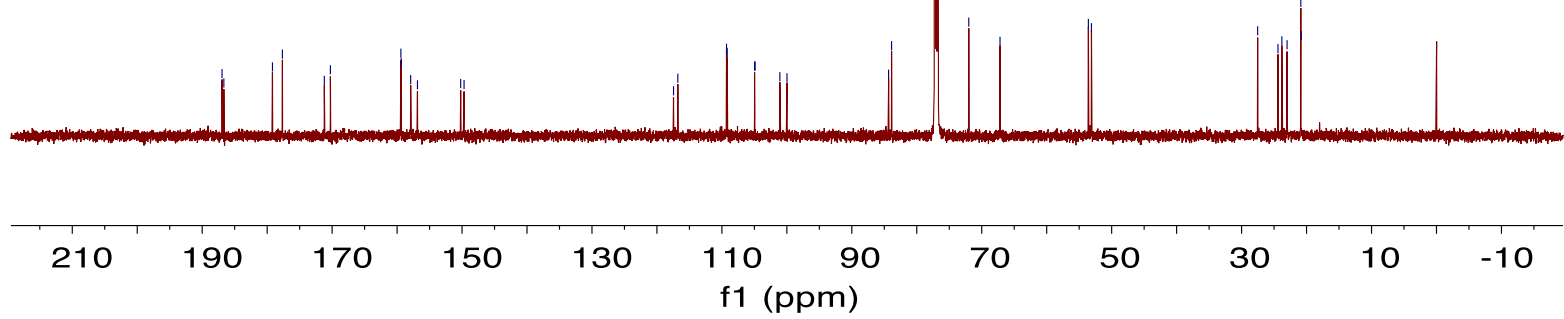

Figure S12. ${ }^{13} \mathrm{C}$ NMR spectrum of $10 a^{\prime}$-epi-rugulotrosin $\mathrm{A}(\mathbf{1 0})$ in $\mathrm{CDCl}_{3}$ at $150 \mathrm{MHz}$. 


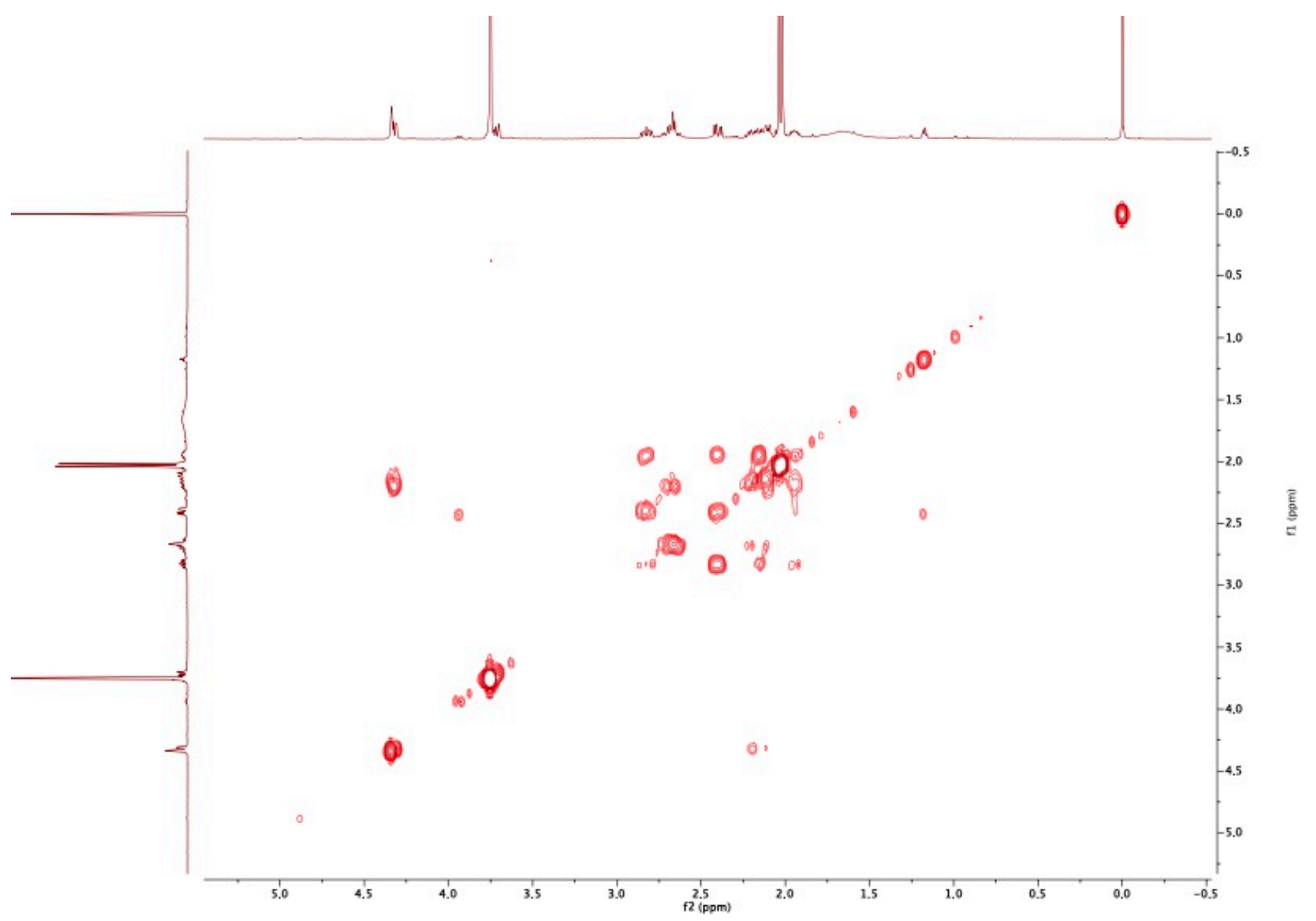

Figure S13. ${ }^{1} \mathrm{H}-{ }^{1} \mathrm{H}$ COSY of $10 \mathrm{a}^{\prime}$-epi-rugulotrosin $\mathrm{A}(\mathbf{1 0})$ in $\mathrm{CDCl}_{3}$.

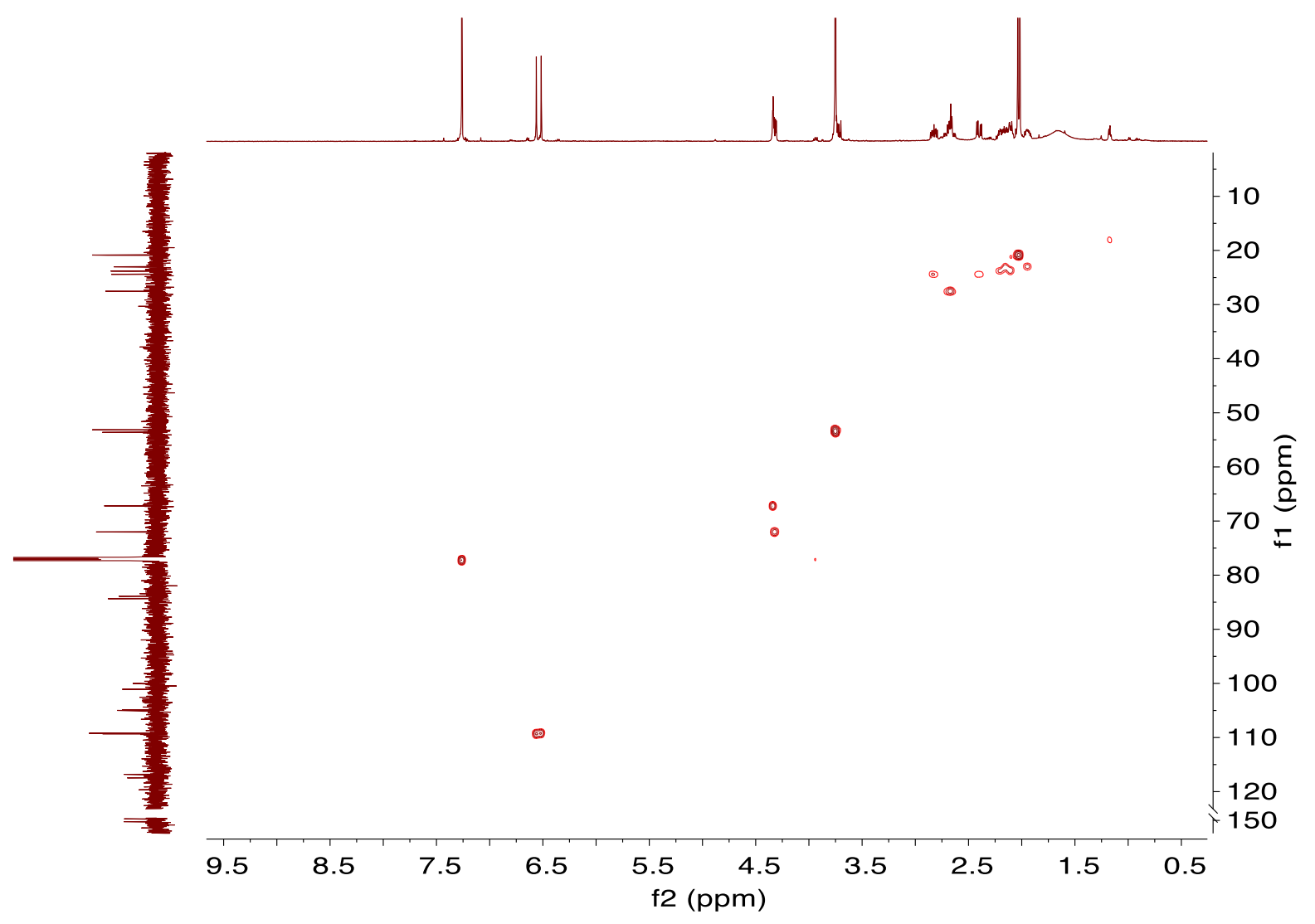

Figure S14. HSQC spectrum of $10 \mathrm{a}^{\prime}$-epi-rugulotrosin A (10) in $\mathrm{CDCl}_{3}$. 


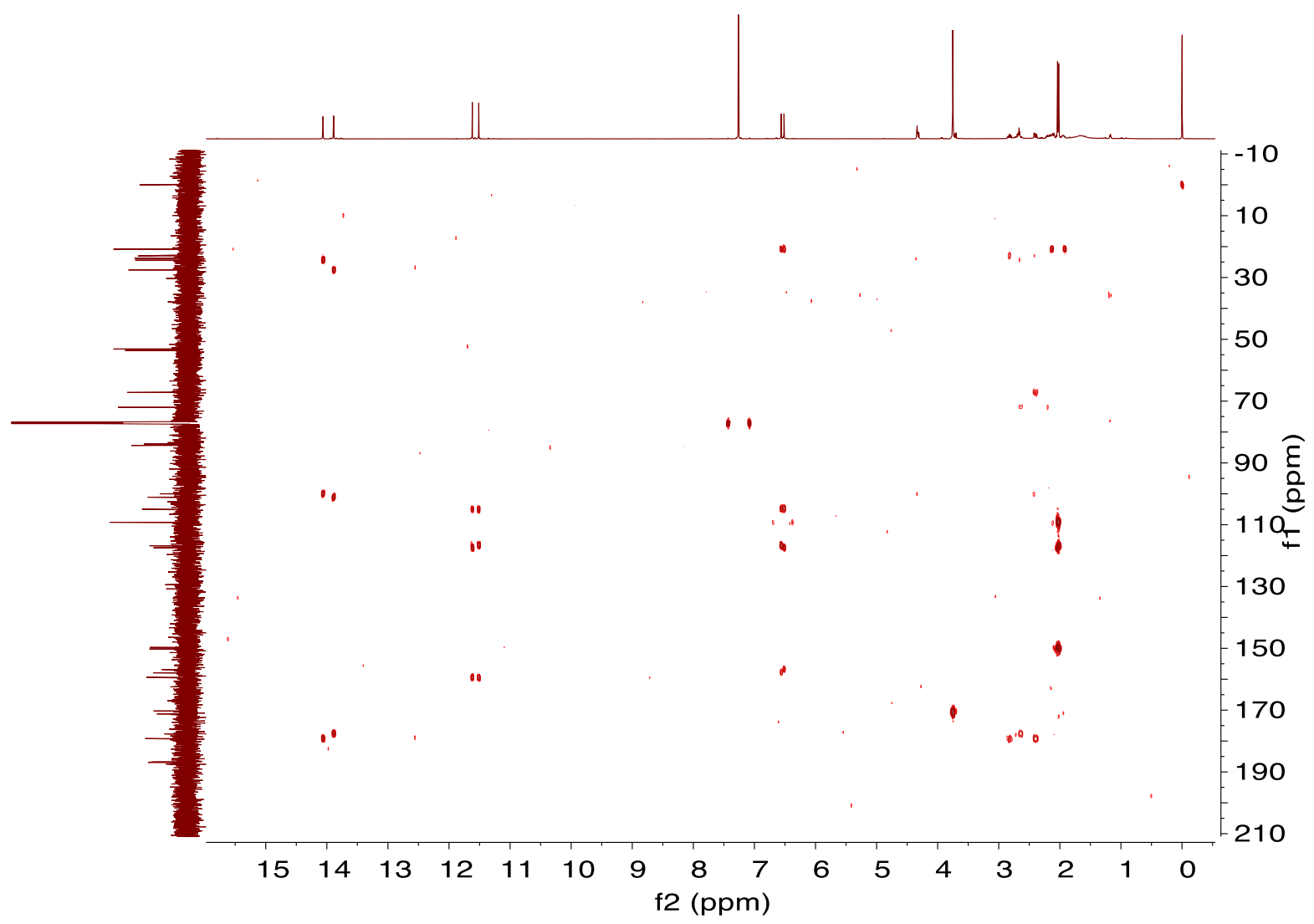

Figure $\mathrm{S} 15$. HMBC of $10 \mathrm{a}^{\prime}$-epi-rugulotrosin $\mathrm{A}(\mathbf{1 0})$ in $\mathrm{CDCl}_{3}$.

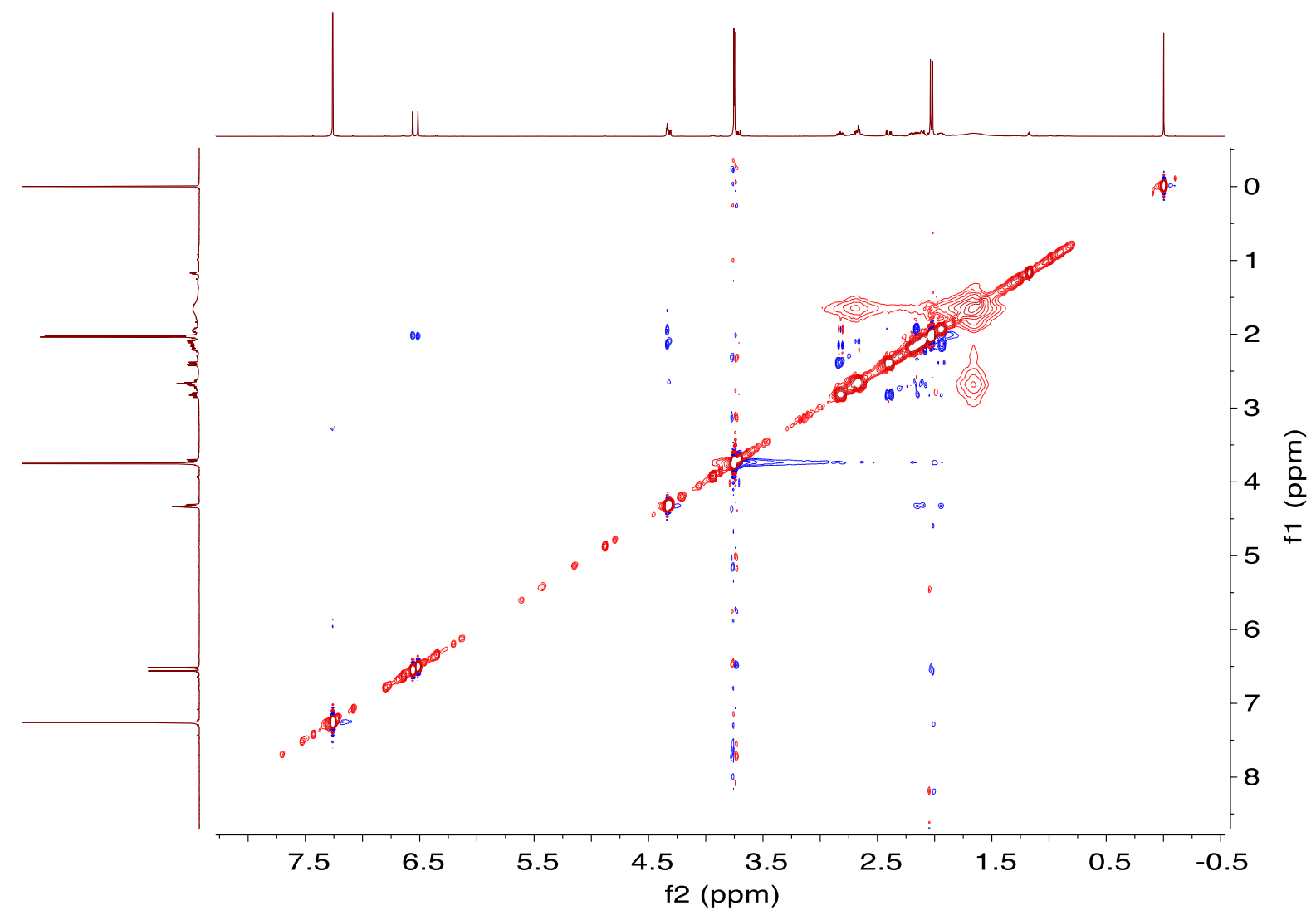

Figure S16. NOESY spectrum of $10 a^{\prime}$-epi-rugulotrosin $\mathrm{A}(\mathbf{1 0})$ in $\mathrm{CDCl}_{3}$. 
<smiles>C=C1CCC1</smiles>

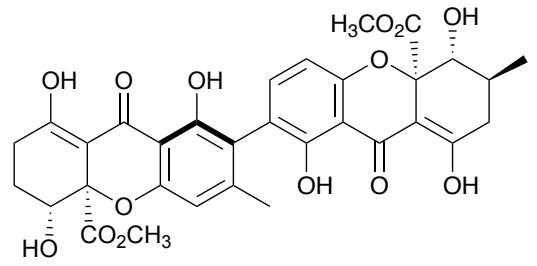

11

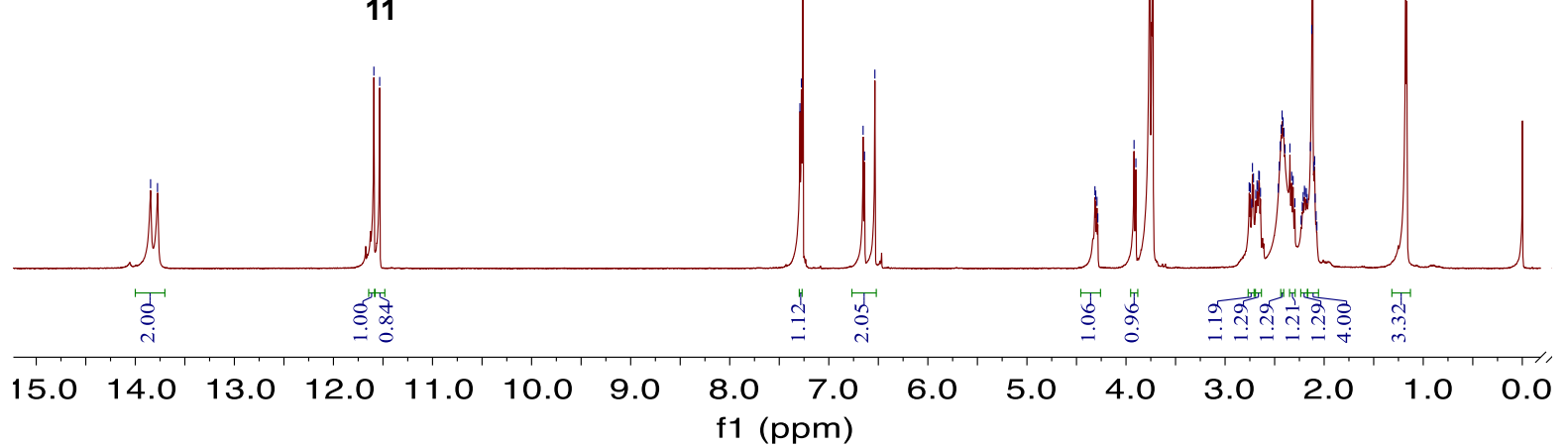

Figure S17. ${ }^{1} \mathrm{H}$ NMR spectrum of versixanthone $\mathrm{H}(\mathbf{1 1})$ in $\mathrm{CDCl}_{3}$ at $600 \mathrm{MHz}$.

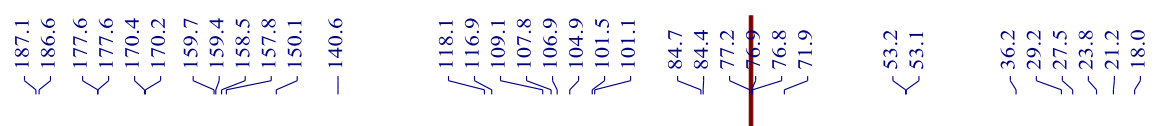<smiles></smiles>

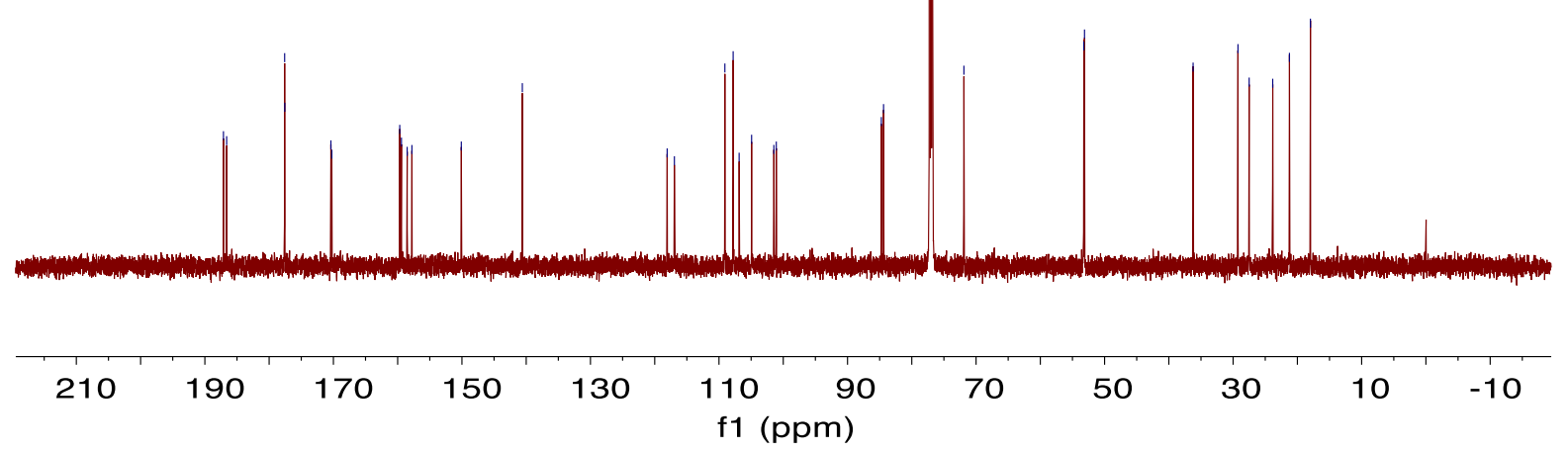

Figure S18. ${ }^{13} \mathrm{C}$ NMR spectrum of versixanthone $\mathrm{H}(11)$ in $\mathrm{CDCl}_{3}$ at $150 \mathrm{MHz}$. 


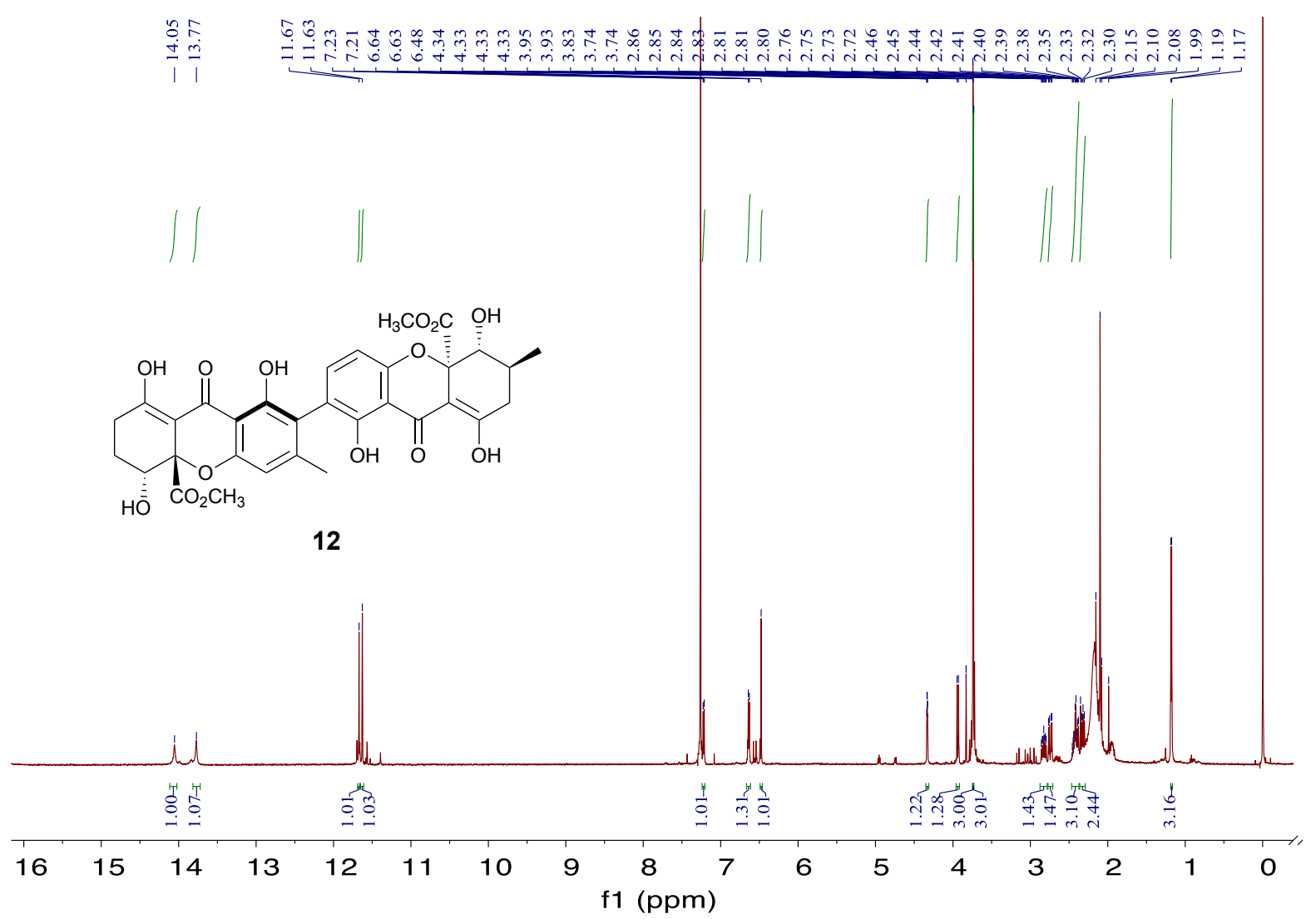

Figure S19. ${ }^{1} \mathrm{H}$ NMR spectrum of $10 \mathrm{a}^{\prime}$-epi-versixanthone $\mathrm{H}(\mathbf{1 2})$ in $\mathrm{CDCl}_{3}$ at $600 \mathrm{MHz}$.

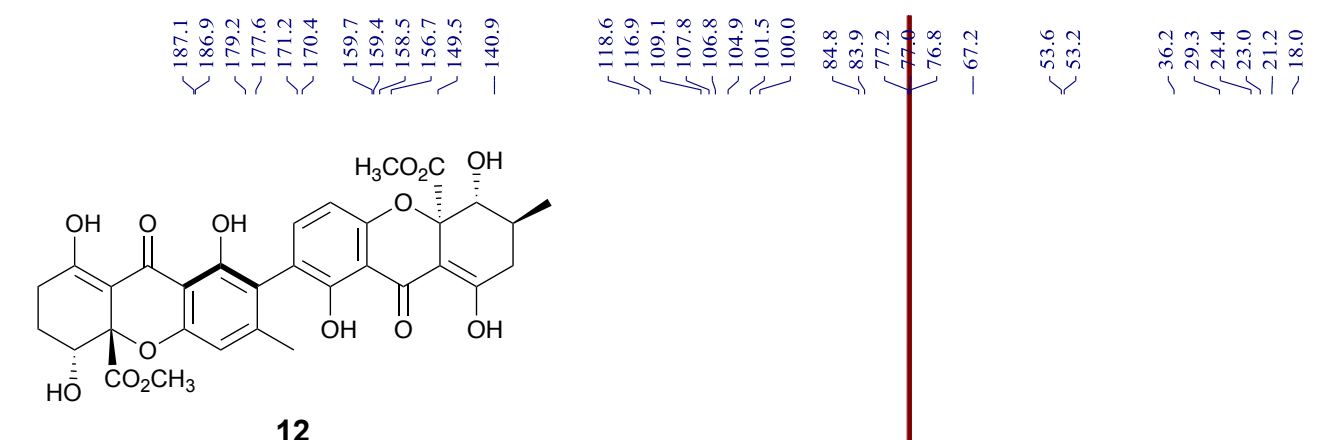

12

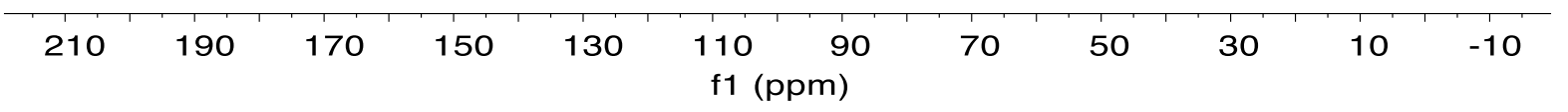

Figure S20. ${ }^{13} \mathrm{C}$ NMR spectrum of $10 \mathrm{a}^{\prime}$-epi-versixanthone $\mathrm{H}(\mathbf{1 2})$ in $\mathrm{CDCl}_{3}$ at $150 \mathrm{MHz}$. 


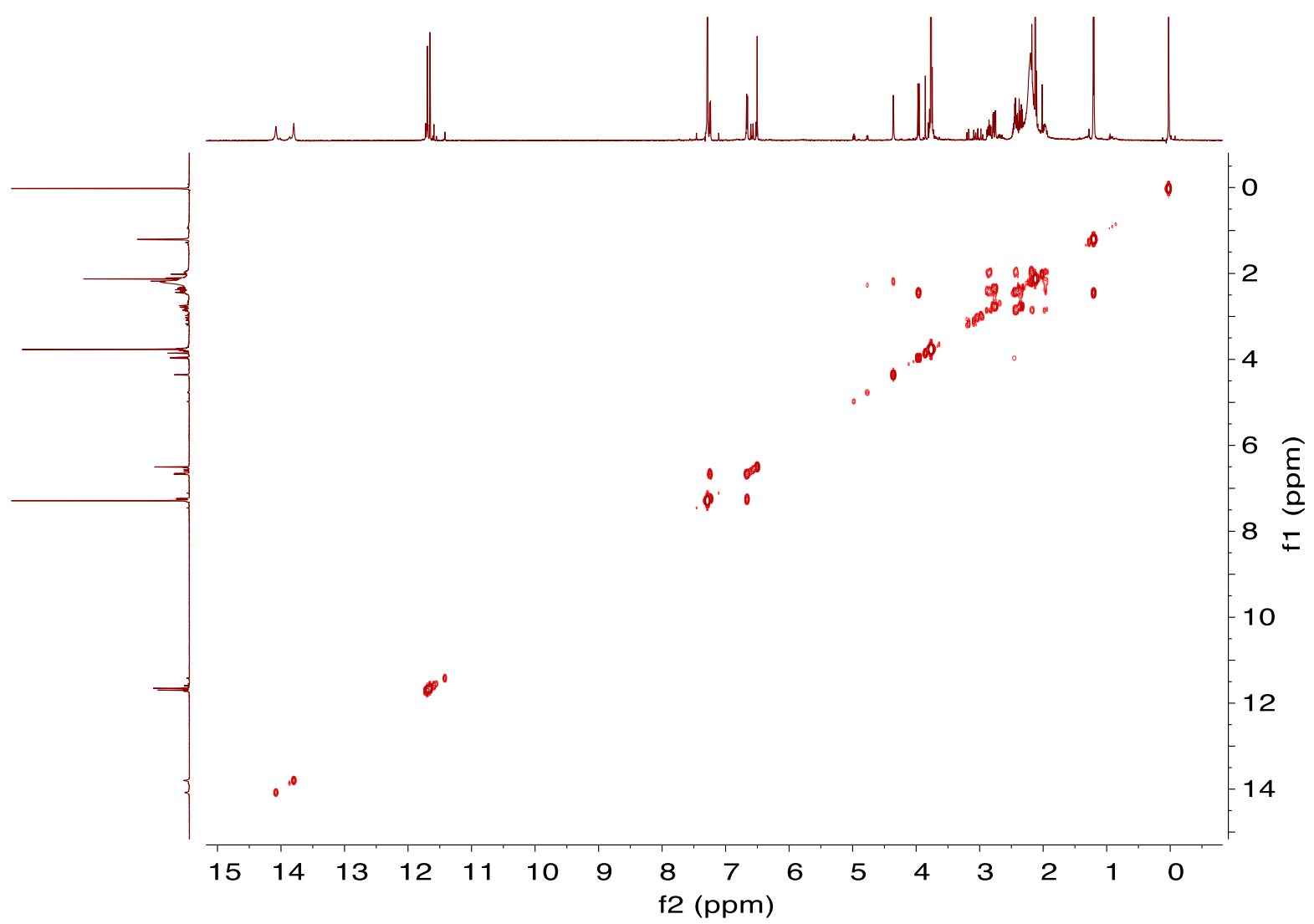

Figure S21. ${ }^{1} \mathrm{H}-{ }^{1} \mathrm{H}$ COSY of $10 \mathrm{a}^{\prime}$-epi-versixanthone $\mathrm{H}(\mathbf{1 2})$ in $\mathrm{CDCl}_{3}$.

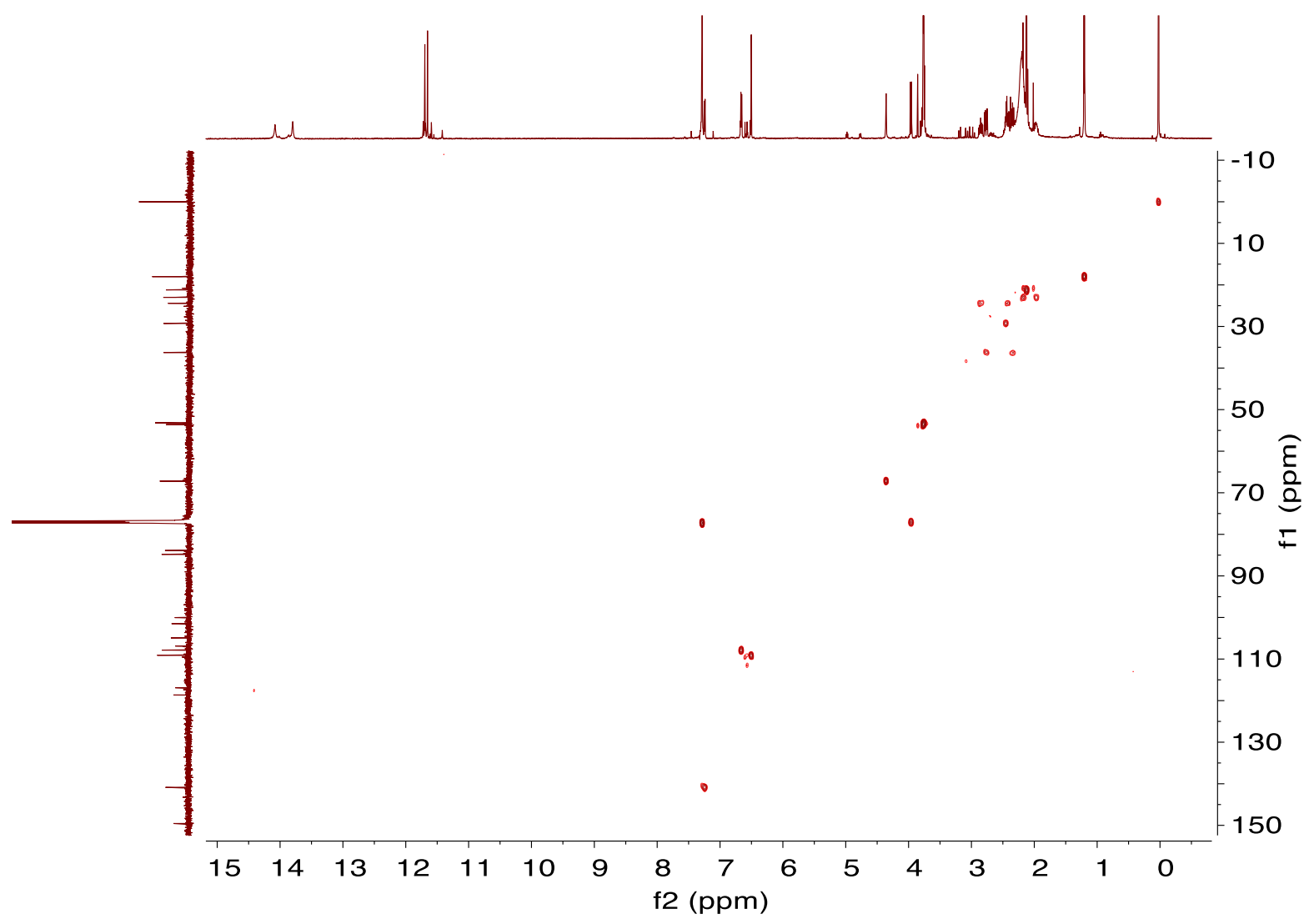

Figure S22. HSQC spectrum of $10 \mathrm{a}^{\prime}$-epi-versixanthone $\mathrm{H}(\mathbf{1 2})$ in $\mathrm{CDCl}_{3}$. 


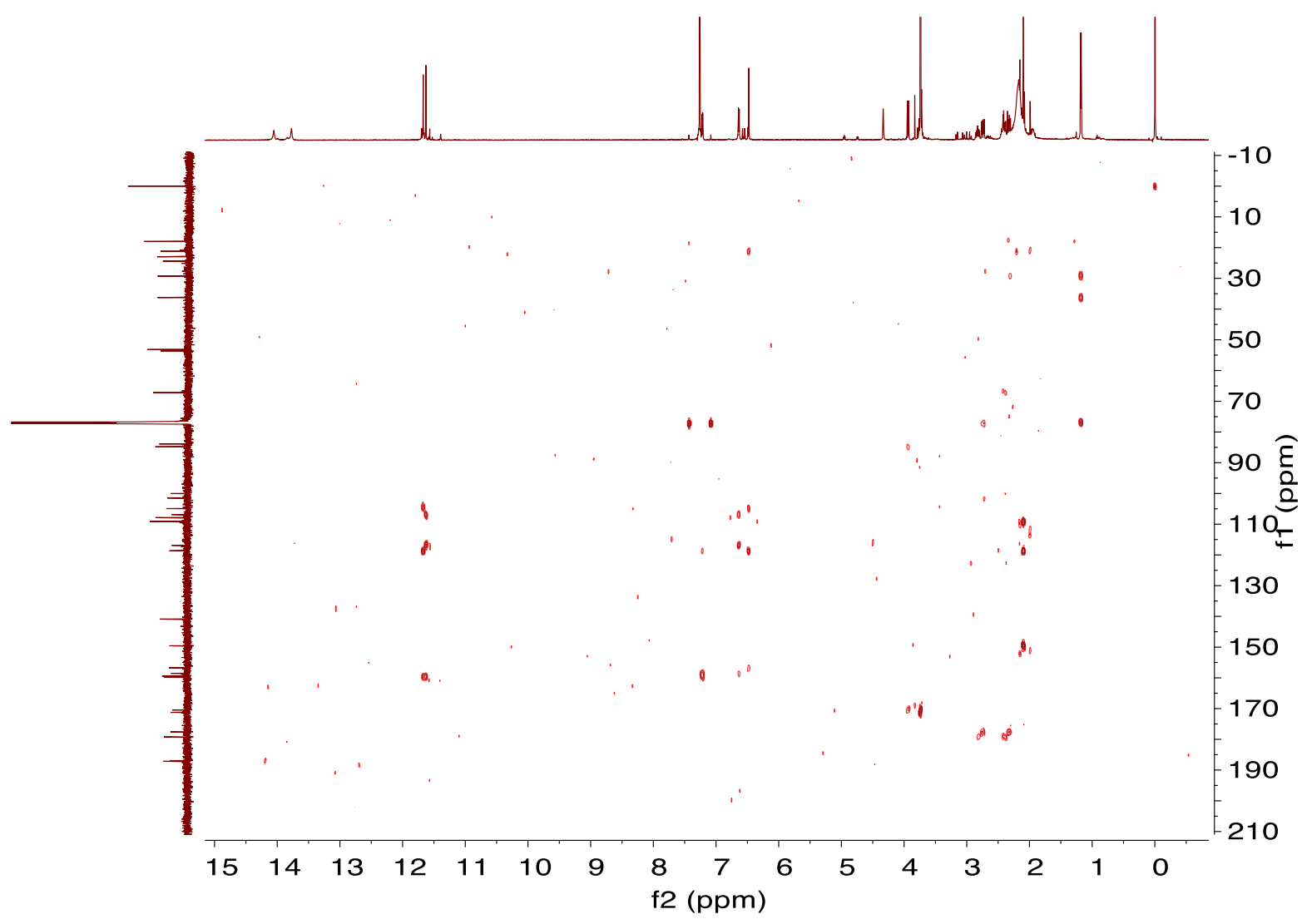

Figure S23. HMBC of 10a'-epi-versixanthone $\mathrm{H}(\mathbf{1 2})$ in $\mathrm{CDCl}_{3}$.

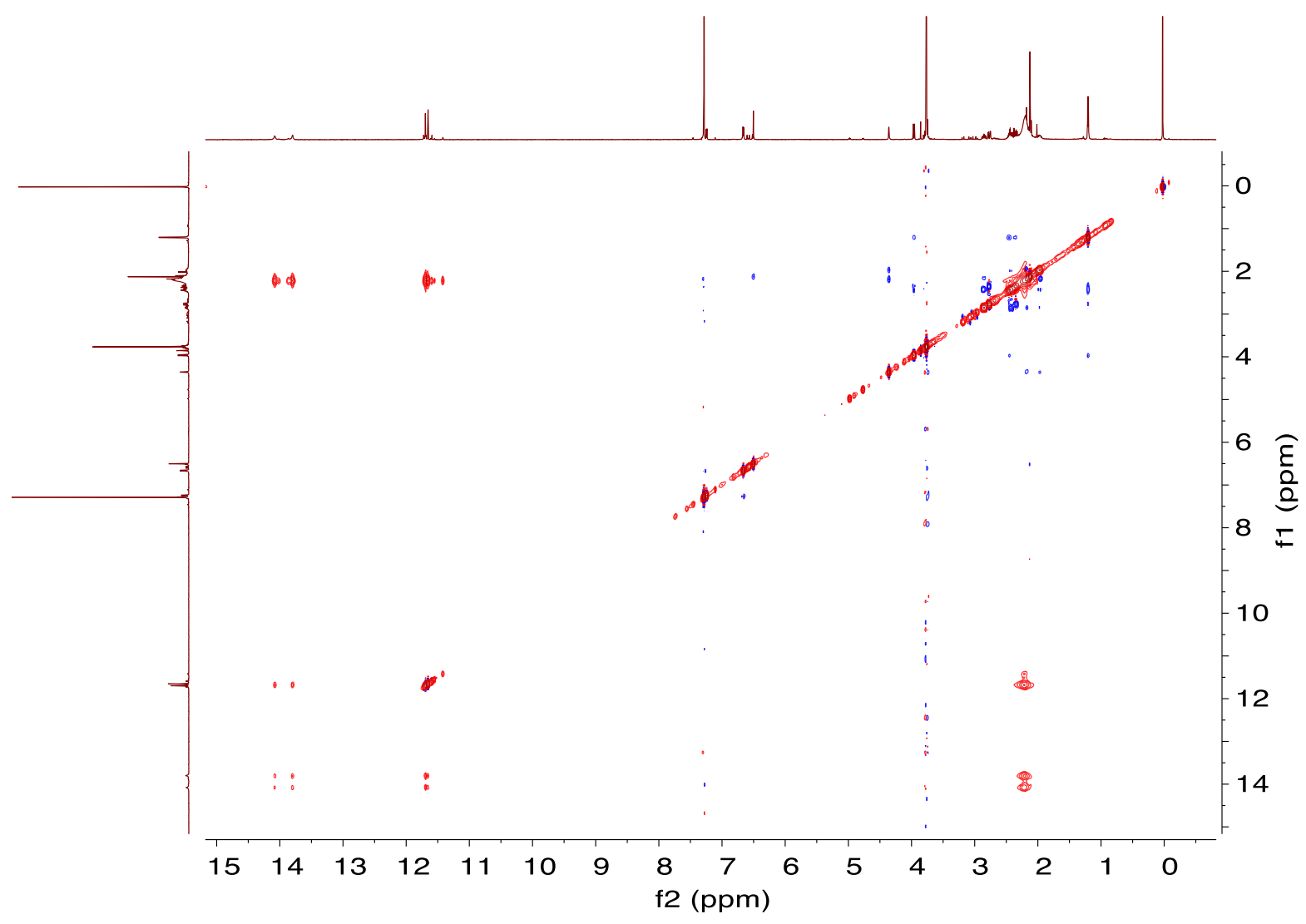

Figure S24. NOESY spectrum of $10 \mathrm{a}^{\prime}$-epi-versixanthone $\mathrm{H}(\mathbf{1 2})$ in $\mathrm{CDCl}_{3}$. 


\section{Supplementary Reference:}

1. Wei, X.; Matsuda, Y., Unraveling the fungal strategy for tetrahydroxanthone biosynthesis and diversification. Org. Lett. 2020, 22, 1919-1923. 